$10 / 2.1095820$

- SANDIA REPORT

SAND94-8251 UC- 706

Unlimited Release

Printed January 1995

\title{
Recipes for High Resolution Time-of-Flight Detectors
}

S. J. Anz, T. E. Felter, R. S. Daley, M. L. Roberts, R. S. Williams, and B. V. Hess

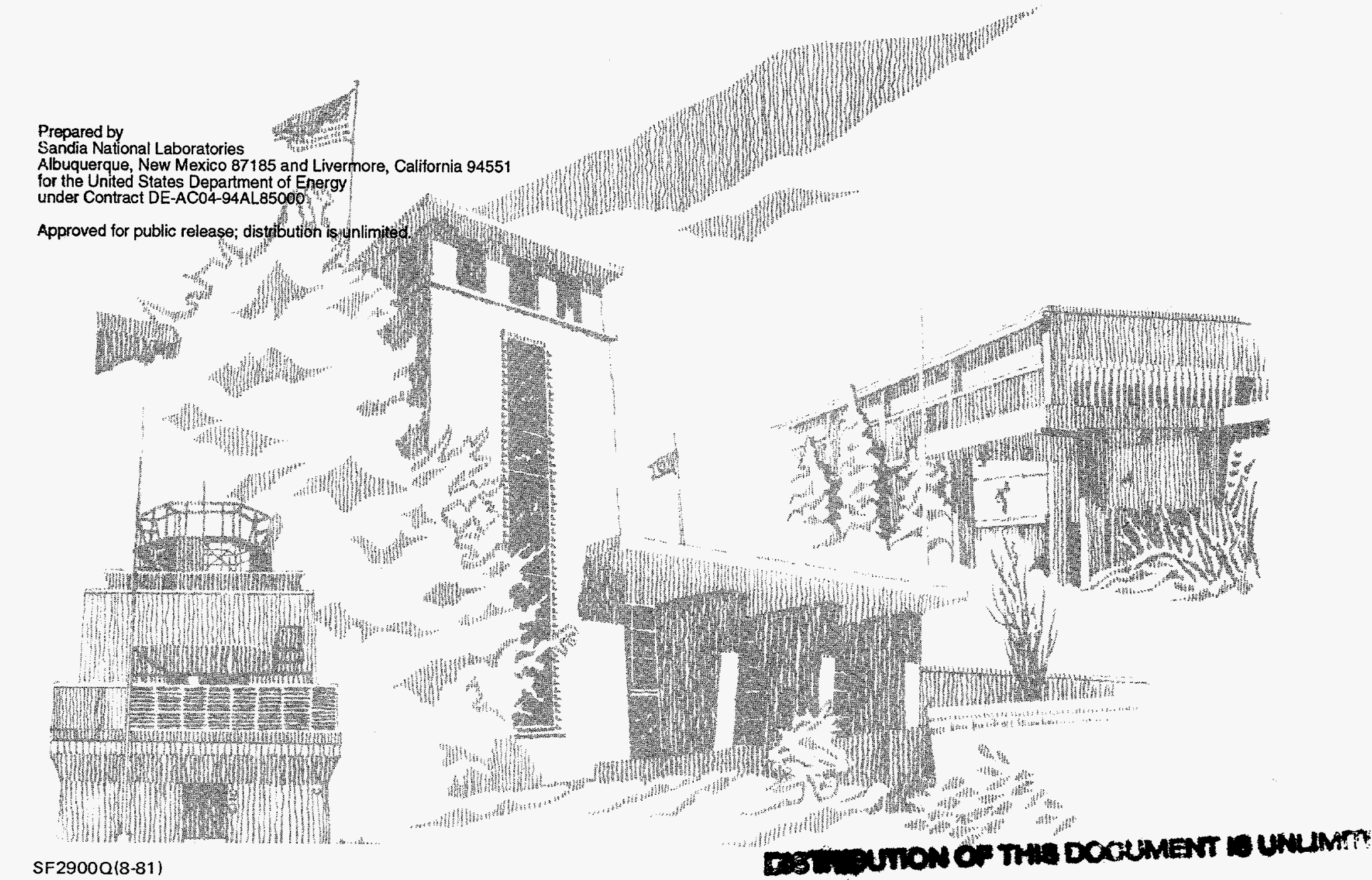


Issued by Sandia National Laboratories, operated for the United States Department of Energy by Sandia Corporation.

NOTICE: This report was prepared as an account of work sponsored by an agency of the United States Government. Neither the United States Government nor any agency thereof, nor any of their employees, nor any of the contractors, subcontractors, or their employees, makes any warranty, express or implied, or assumes any legal liability or responsibility for the accuracy, completeness, or usefulness of any information, apparatus, product, or process disclosed, or represents that its use would not infringe privately owned rights. Reference herein to any specific commercial product, process, or service by trade name, trademark, manufacturer, or otherwise, does not necessarily constitute or imply its endorsement, recommendation, or favoring by the United States Government, any agency thereof or any of their contractors or subconractors. The views and opinions expressed herein do not necessarily state or reflect those of the United States Government, any agency thereof or any of their contractors or subcontractors.

This report has been reproduced from the best available copy.

Available to DOE and DOE contractors from:

Office of Scientific and Technical Information

P. O. Box 62

Oak Ridge, TN 37831

Prices available from (615) 576-8401, FTS 626-8401

Available to the public from:

National Technical Information Service

U.S. Department of Commerce

5285 Port Royal Rd.

Springfield, VA 22161 


\section{DISCLAIMER}

\section{Portions of this document may be illegible in electronic image products. Images are produced from the best available original document.}


SAND94-8251

Unlimited Release

Printed January 1995

\title{
Recipes For High Resolution Time-of-Flight Detectors
}

\author{
Samir J. Anz1, 2, Thomas E. Felter2 ${ }^{2}$ Richard S. Daley ${ }^{3,4}$, Mark L. Roberts ${ }^{3}$, \\ R. Stanley Williams ${ }^{1}$ and B.V. Hess ${ }^{2}$
}

\begin{abstract}
We discuss the dynamics, construction, implementation and benefits of a time-offlight (TOF) detector with count rates an order of magnitude higher and resolution three to four times better than that obtainable with a surface barrier detector. The proper use of design criteria for a time-of-flight detector is outlined, and the determination of a TOF detector's total relative timing error and how this value determines the mass resolution are illustrated using a graphical analysis. We present simulation and experimental examples employing light ions and discuss advantages and pitfalls of medium-energy heavy ion TOF spectrometry.
\end{abstract}

${ }^{1}$ UCLA, Department of Chemistry and Biochemistry, and Solid State Science Center 405 Hilgard Ave. Los Angeles, CA 90024 - USA

2Sandia National Laboratories, Livermore, CA 94551 - USA

3Lawrence Livermore National Laboratories, Livermore, CA 94551 - USA

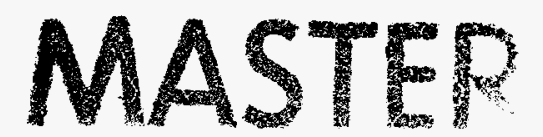

4Present address: Foothill College, Department of Physical Science, 12345 El Monte Rd.

Los Altos Hills, CA 94022 - USA 


\section{ACKNOWLEDGMENT}

We acknowledge useful discussions with A. E. Pontau, D. H. Morse, D. W.

Heikkinen, I. D. Proctor, A. J. Antolak, G.T. Olona, M. L. Hildner, M. I. Baskes, and G. J.

Thomas. A. E. Pontau is further thanked for support and encouragement. S.J. Anz

thanks Associated Western Universities for a grant funded by Sandia's DP sector student initiative.

This work was supported by the U.S. Department of Energy under Contract DEAC04-94AL85000. 


\section{TABLE OF CONTENTS}

I. Introduction

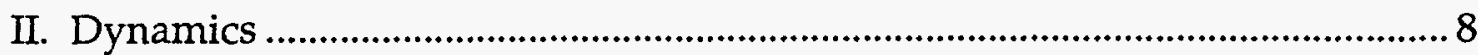

2.1 Binary collisions ................................................................................... 8

2.1.2 Binary Collisions - Two Target Masses ...............................................

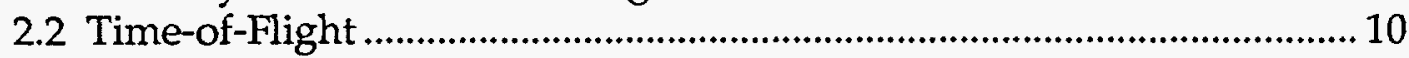

2.3 Time-to-Energy Transformation ........................................................... 12

2.4 Straggling ............................................................................................... 13

III. TOF Spectrometer Construction ........................................................................ 14

3.1 Experimental Setup................................................................................. 14

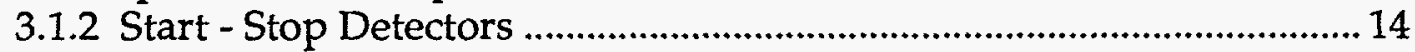

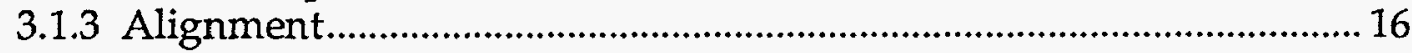

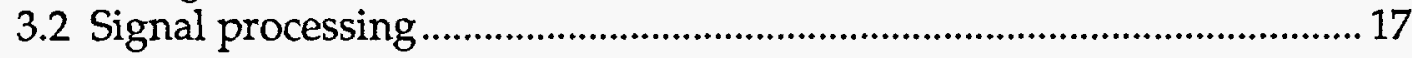

IV. TOF Spectrometer Resolution and Efficiency .................................................... 19

4.1 Electronic Timing Resolution ................................................................ 19

4.2 Total Relative Timing Resolution ........................................................... 20

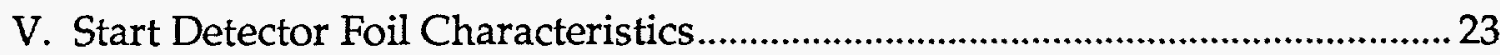

5.1 Energy and Spatial Spread of Transmitted Projectiles ............................. 23

5.2 Influence of Foil Thickness ........................................................................... 24

5.3 TRIM Precautions ...................................................................................... 25

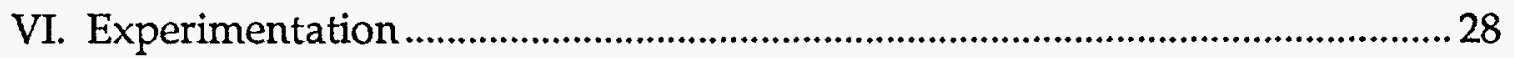

6.1 Performance and Efficiency ...................................................................... 28

6.2 Resolution ............................................................................................. 28

VII. Conclusion and Future Work ........................................................................ 30

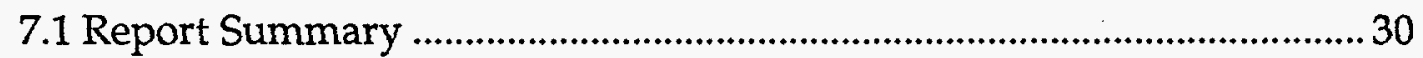

7.2 Future Experiments and Designs................................................................... 32

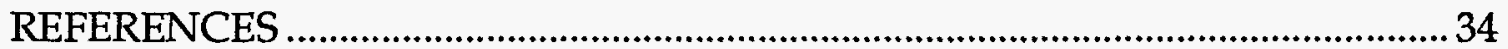




\section{Recipes For High Resolution Time-of-Flight Detectors}

\section{Introduction}

Many of the limitations inherent in High and Medium Energy Ion Scattering, HEIS and MEIS, using a surface barrier detector have been overcome by the recent implementation of Time of Flight, TOF, detectors[1, 2]. Improvements include: 1) higher count rates, 2) better energy resolution, 3) greater immunity to damage and 4) the absence of channeling in the detector. In the TOF technique, the measurement of a particle's flight time over a known path gives it's velocity and hence it's energy[3]. The fast response time of chevron microchannel plate (MCP) detectors and their electronics allow count rates as high as several hundred thousand counts per second and the accurate timing leads to excellent energy resolution. For surface barrier detectors, the count rate is limited to approximately ten thousand counts per second by the time dependence of the associated electronics for the shaping constant applied to the signal pulse and by the even slower conversion time of analog to digital converters. Resolution is generally set by the noise in the preamplifier and is typically on the order of $10 \mathrm{keV}$. In addition, detector performance is degraded by localized radiation damage caused by the energetic ions. This damage results in a loss of charge collection efficiency in the damaged region which in turn causes shifts and loss of resolution in the energy spectrum. Replacement of the detector is expensive and inconvenient.

TOF detection is well-suited to thin film and materials analysis using heavy ion scattering. The use of heavy instead of hydrogen or helium ions offers significant advantages: mass resolution is considerably enhanced on kinematic grounds; surface resolution is enhanced due to the larger $\mathrm{dE} / \mathrm{d} x$ values of heavy ions; and the sensitivity 
to low level concentrations in the target material is enhanced while elements lighter than the projectile become invisible as a result of the quadratic dependence of the scattering cross-section on nuclear charge[1]. These advantages are not accessible with surface barrier detectors. With heavy ions, the degradation of surface barrier detectors by radiation is increased, while signal quality and signal-to-noise are diminished by several factors: a shallow penetration depth; a higher charge carrier recombination resulting from a higher ionization density; an increase in non-ionizing nuclear collisions; and a higher probability of channeling into the detector due to larger critical angles[4].

High resolution energy spectra and immunity from the above mentioned conditions can be acquired with magnetic spectrometers. However, high price, extremely low mass acceptance, and the need for a final charged state of the scattered particle make magnetic spectrometers less versatile than TOF detectors. The latter offer low cost, large mass acceptance for both ions and neutrals, and virtually no performance degradation by radiation damage[ 1 -5]. In addition, dispensing with the stringent geometric conditions and accurate mechanical alignment needed for production of highly uniform magnetic fields simplifies construction and allows for the resolution, in most cases, to be limited by the electronics. Moreover, unlike magnetic spectrometers, which require scanning over the desired energy range, TOF spectrometers collect all energies simultaneously and thus reduce spectrum acquisition time from tens of seconds to microseconds[3].

In the next sections, we describe the dynamics, construction, implementation and benefits of a TOF detector system. We also discuss some of the advantages and disadvantages of such a TOF system through comparison to commonly used surface barrier detectors. 


\section{Dynamics}

In this section, we review the dynamics of the scattering and detection processes, including energy straggling, that are important for characterizing detectors.

\subsection{Binary collisions}

Figure 1 illustrates the scattering geometry in the laboratory (LAB) coordinate system for a binary collision. From conservation of energy and momentum the kinematic factor for the projectile, $\mathrm{K}_{\mathrm{p}}$, for a binary collision in the LAB coordinate system is $[6,7]$ :

$$
K_{p}=\frac{E_{p}}{E_{o}}=\left[\frac{\cos \theta_{p} \pm \sqrt{\gamma^{-2}-\sin ^{2} \theta_{p}}}{(1+\gamma)}\right]^{2}, .
$$

where $E_{o}$ and $E_{p}$ are the initial and final projectile energies, $\theta_{p}$ is the projectile scattering angle in the LAB coordinate system, and $\gamma=\frac{\mathrm{M}_{\mathrm{P}}}{\mathrm{M}_{\mathrm{T}}}$, is the ratio of the projectile and target masses.

When the projectile mass is smaller than the target mass, $\gamma<1$, only the solution associated with the plus sign is physical and $\theta_{\mathrm{p}}$ can vary from 0 (no scattering) to $\pi\left(180^{\circ}\right.$ back-scattering). For the case of the projectile mass being equal to or larger than the target mass, $\gamma \geq 1$, the solutions for both the plus and minus signs are physical, resulting in a double valued kinematic factor, and only forward scattering can occur with the range of scattering angles given by:

$$
0 \leq \theta_{\mathrm{p}} \leq \arcsin \gamma^{-1}=\theta_{\mathrm{p} \max } \leq \frac{\pi}{2} \text {, }
$$


where $\arcsin \gamma^{-1}$ is the maximum angle of scattering, $\theta_{\text {pmax }}$, for a given projectile-target mass ratio, $\gamma$

For the case of $90^{\circ}$ scattering, equation 1 reduces to:

$$
K_{p}=\frac{E_{p}}{E_{o}}=\frac{M_{T}-M_{P}}{M_{T}+M_{P}}\left(90^{\circ} \text { Scattering }\right) .
$$

For the special case of billiard-like collisions, i.e. $\gamma=1$, all the incident energy is transferred to the target and the projectile is left at rest.

For $180^{\circ}$ back-scattering, the kinematic factor is minimized:

$$
K_{p}=\frac{E_{p}}{E_{o}}=\left[\frac{M_{T}-M_{P}}{M_{T}+M_{P}}\right]^{2} \quad\left(180^{\circ} \text { Scattering }\right) \text {. }
$$

Further application of conservation of energy allows the kinematic factor for the recoiled target particle, $K_{T}=E_{T} / E_{o}$, to be determined:

$$
\begin{gathered}
\mathrm{K}_{\mathrm{P}}+\mathrm{K}_{\mathrm{T}}=1 \\
\therefore \mathrm{K}_{\mathrm{T}}=\frac{\mathrm{E}_{\mathrm{T}}}{\mathrm{E}_{\mathrm{o}}}=1-\frac{\mathrm{E}_{\mathrm{p}}}{\mathrm{E}_{\mathrm{o}}}=\frac{4 \gamma}{(1+\gamma)^{2}} \cos ^{2} \theta_{\mathrm{T}}
\end{gathered}
$$

where $E_{\mathrm{T}}$ is the final target energy and $\theta_{\mathrm{T}}$ is the target recoil angle in the LAB coordinate system. For any value of $\gamma, \theta_{\mathrm{T}}$ can vary from 0 to $\frac{\pi}{2}$.

\subsubsection{Binary Collisions - Two Target Masses}

The difference in projectile scattered energy for two target masses is equal to the difference in the kinematic factor for the two target masses multiplied by the incident projectile energy: 


$$
\left|E_{\mathrm{p}}\left(\mathrm{M}_{\mathrm{T}_{1}}\right)-\mathrm{E}_{\mathrm{p}}\left(\mathrm{M}_{\mathrm{T}_{2}}\right)\right|=\delta \mathrm{E}_{\mathrm{p}}=\left|\mathrm{K}_{\mathrm{p}}\left(\mathrm{M}_{\mathrm{T}_{1}}\right)-\mathrm{K}_{\mathrm{p}}\left(\mathrm{M}_{\mathrm{T}_{2}}\right)\right| \cdot \mathrm{E}_{\mathrm{o}}=\delta \mathrm{K}_{\mathrm{p}} \cdot \mathrm{E}_{\mathrm{o}}
$$

The relative difference in projectile energy for the two target masses is:

$$
\frac{\delta E_{p}}{E_{p}}=\frac{\delta K_{p} \cdot E_{o}}{E_{p}}=\frac{\delta K_{p}}{K_{p}}
$$

which for light projectiles scattering off heavy target masses reduces to:

$$
\frac{\delta \mathrm{E}_{\mathrm{p}}}{\mathrm{E}_{\mathrm{p}}}=\delta \mathrm{K}_{\mathrm{p}}
$$

As an illustration of these equations, figure 2 shows both the absolute and relative differences in the kinematic factors for target masses corresponding to the two isotopes of uranium with: 1) various scattering angles as a function of projectile mass and 2) various projectile masses as a function of scattering angle. Note that the mass resolution -i.e. the relative change in the kinematic factor, $\frac{\delta \mathrm{K}_{\mathrm{p}}}{\mathrm{K}_{\mathrm{p}}}$, per change in the target mass, $\delta \mathrm{M}_{\mathrm{T}}$ - is greatest at a scattering angle of $180^{\circ}$ and drastically decreases at scattering angles below $90^{\circ}$. Also note that the closer the projectile mass is to the target mass the greater the relative change in the kinematic factor per change in the target mass. Consequently, for a constant scattering angle, optimal mass resolution is obtained when the projectile and target masses are about equal, hence the appeal of heavy ions[8].

\subsection{Time-of-Flight}

The time, $t$, measured for a free flight particle of energy $E$ and mass $m$ to traverse a distance $\mathrm{L}$ is given by:

$$
\mathrm{t}(\mathrm{ns}: \mu \mathrm{s}) \approx 72 \cdot\left(\frac{\mathrm{m}(\mathrm{amu})}{\mathrm{E}(\mathrm{MeV}: \mathrm{eV})}\right)^{1 / 2} \cdot \mathrm{L}(\mathrm{m})
$$


The free flight time dynamics of equation 9 are such that the degree of mass and energy separation increases with flight time and thus flight path length.

Once a particle's time of flight is measured, its energy is simply determined by:

$$
E(M e V: e V) \approx m(a m u) \cdot\left(\frac{72 \cdot L(m)}{t(n s: \mu s)}\right)^{2}
$$

From this functional form, the total relative energy error is found to be twice the total relative timing error:

$$
\frac{\delta \mathrm{E}}{\mathrm{E}}=\frac{2 \delta \mathrm{t}}{\mathrm{t}},
$$

where $\delta t$ is the absolute timing error. Furthermore, for a constant $\delta t$, the absolute energy error, $\delta \mathrm{E}$, decreases with energy[9]:

$$
\delta \mathrm{E} \sim \mathrm{E}^{3 / 2} \delta \mathrm{t}
$$

making TOF appealing for low and medium energy experiments[1, 2, 8 - 11].

Upon substitution of equation 7 into equation 11 , one obtains a condition for the total relative timing error needed to resolve two masses with kinematic factors differing by $\delta K_{\mathrm{p}}$ :

$$
\frac{\delta \mathrm{t}}{\mathrm{t}} \leq \frac{\delta \mathrm{K}_{\mathrm{p}}}{2 \mathrm{~K}_{\mathrm{p}}}
$$

Sufficient relative kinematic or mass resolution, given by the equality, is achieved when the time spread, $\delta \mathrm{t}$, for ions scattering off the same target mass just equals the flight time difference between ions scattering off the two different target masses to be identified. The inequality is introduced since reducing the total relative timing error increases the mass resolution. As an example, in order to kinematically separate gallium and arsenic 
with hydrogen at a scattering angle of $90^{\circ}$, a total relative timing error of less than $0.1 \%$ is required.

\subsection{Time-to-Energy Transformation}

The intrinsic time domain for time-of-flight spectra is non-linear with respect to target mass and scattered projectile energy, as is evident from equation 9. It is more practical and meaningful to display spectra in the linear energy domain. To make the transformation from the time domain to the energy domain, events(counts) must be conserved, i.e. the number of events, $\mathrm{N}(\mathrm{t})$, in a time bin, $\delta \mathrm{t}$, for a time domain spectrum must equal the number of events, $\mathrm{N}(\mathrm{E})$, in the corresponding energy bin, $\delta \mathrm{E}$, for the energy domain spectrum. The transformation is as follows:

$$
\begin{aligned}
N(E) \cdot \delta E & =N(t) \cdot \delta t \\
N(E) & =N(t) \cdot\left|\frac{\delta t}{\delta E}\right| \\
& =N(t) \cdot \frac{t}{2 E} .
\end{aligned}
$$

The term $\left|\frac{\delta \mathrm{t}}{\delta \mathrm{E}}\right|$ is the Jacobian for time to energy transformation. The Jacobian dictates the relation between bins in the time domain and corresponding bins in the energy domain. That is, for a time domain spectrum with constant bin width, the Jacobian will transfer events in time to their corresponding bins in energy while scaling the energy bin widths. For two energy events $E_{1}$ and $E_{2}$, for example, the energy bin width scales as follows:

$$
\delta \mathrm{E}_{2}=\left(\frac{\mathrm{E}_{2}}{\mathrm{E}_{1}}\right)^{3 / 2} \delta \mathrm{E}_{1} \quad(\text { for constant } \delta \mathrm{t})
$$




\subsection{Straggling}

Particles traversing a foil interact inelastically with the electrons and nuclei of the medium. The degree of energy loss per interaction is discrete and subject to statistical fluctuation. The transmitted energy for a projectile is therefore subject to statistics. The second moment of the transmitted energy distribution, $\Omega$, for projectiles with the same incident velocity is known as the energy straggling and is a fundamental limit to the resolution of an experiment.

For projectiles with atomic number $Z_{1}$ traversing a foil of thickness $t$, atomic density $N$, and atomic number $Z_{2}$, the degree of energy straggling was first theorized by Bohr[12] to be,

$$
\Omega_{\text {Bohr }}^{2}=4 \pi Z_{1}^{2} e^{4 N Z_{2} t}
$$

This result is general and indicates that the degree of energy straggling is independent of projectile energy. Furthermore, it shows that energy straggling increases with the square root of the foil electron density, $\mathrm{NZ}_{2}$, and increases with foil thickness, $\mathrm{t}$.

For light element projectiles such as $\mathrm{H}^{+}$and $\mathrm{He}^{+}$, interactions are primarily with the electrons of the foil material. The distribution of transmitted energies for these elements after passage through a foil is Gaussian. That is, the probability, within $\mathrm{d} \Delta \mathrm{E}$, of finding a transmitted energy $\Delta \mathrm{E}$ from the mean transmitted energy is:

$$
\mathrm{P}(\Delta \mathrm{E}) \mathrm{d} \Delta \mathrm{E}=\frac{\exp \left[-\Delta \mathrm{E}^{2} / 2 \Omega_{\text {Bohr }}^{2}\right]}{\left(2 \pi \Omega_{\mathrm{Bohr}}^{2}\right)^{1 / 2}} \mathrm{~d} \Delta \mathrm{E}
$$




\section{TOF Spectrometer Construction}

\subsection{Experimental Setup}

The TOF detector is situated on a beam line at a scattering angle of $90^{\circ}$. The beam line is connected via a dipole magnet, used for projectile mass selection, to two ion beam accelerators: a $200 \mathrm{kV}$ implanter powered by a stable solid-state high voltage supply and a $700 \mathrm{kV}$ Van de Graaff. Ions of various mass from either machine can be used with an adjustable energy range from $20 \mathrm{keV}-700 \mathrm{keV}$ and with variable beam size. The TOF detector, schematically illustrated in figure 3 , uses a design similar to that of D'Erasmo et al.[13] and Starzecki et al.[14] which incorporates a start and stop detector for determination of flight time. One advantage of the detector is that it is used with a continuous rather than a pulsed beam. The start detector makes the determination of time zero rather direct as compared to pulsed beams. In pulsed beam TOF the total time of flight includes the time from ion beam pulsing to sample impact. Unfortunately, this time can not always be compensated for correctly, thereby leaving the true flight time from sample to detector uncertain[15].

\subsubsection{Start - Stop Detectors}

The appeal of the start detector, shown in figure 4, is its engineering simplicity, ease of construction and straightforward operation. The detected particles first pass through a thin, $19.4 \mu \mathrm{g} / \mathrm{cm}^{2}$ ( $858 \AA$ ), carbon foil mounted perpendicular to the particle trajectory with an entrance aperture of $6.4 \mathrm{~mm}$. The start signal arises from secondary electrons emitted from the foil which are accelerated to $800 \mathrm{eV}$ by the electric field between the foil and acceleration grid mounted on the block. Meanwhile, an additional grid is mounted in front of the foil and kept at the same potential as the block. This grid 
helps prevent electric field leakage and keeps the electric field homogeneous. A homogeneous electric field preserves the foil's integrity by preventing deformation and breakage due to the large electrostatic forces involved. Once accelerated, the electrons travel in a field free region inside the block prior to intercepting the electric field of the electrostatic mirror.

The electrostatic mirror consists of two parallel wire grids, or "harps", with the wires running parallel to the plane of the figure. The mirror is mounted at a $45^{\circ}$ angle to the electron trajectories and deflects the electrons $90^{\circ}$ toward a $25 \mathrm{~mm}$ diameter chevron type fast $\mathrm{MCP}$ detector with a $50 \Omega$ impedance conical anode. All the grids are made of $25 \mu \mathrm{m}$ diameter $\mathrm{Be}-\mathrm{Cu}$ wire with a spacing of $1.25 \mathrm{~mm}$. The grid configuration gives a calculated transparency of $98 \%$ for each grid or a total transmissivity of greater than $92 \%$ for the entire start detector. One prevailing quality of this design is that the transport of electrons is to first order isochronous - producing the same electron path length and hence same electron time of flight regardless of the point of origin of that electron on the start foil. The electron flight time was calculated to be $4.8 \mathrm{~ns}$ for $800 \mathrm{eV}$ electrons.

While thinner carbon foils would produce sufficient secondary electrons to trigger the start detector and less projectile energy straggle, the $19.4 \mu \mathrm{g} / \mathrm{cm}^{2}$ foil was chosen for its ability to ensure system reliability. Thinner foils broke more frequently and were more difficult to handle and install. The $19.4 \mu \mathrm{g} / \mathrm{cm}^{2}$ thickness foil was resilient and remained intact during accidental voltage drops. The only precaution required to assure foil integrity was during vents and pump downs. Vents were limited by a bleed valve to a rate of $\sim 0.1$ Torr per second initially, rising to $\sim 1$ Torr per second at $\sim 10$ Torr of pressure, and then to $\sim 3$ Torr per second at $\sim 100$ Torr of pressure. Pump down protocols called for rates of $\sim 1$ Torr per second from atmosphere. All valves were opened at $\sim 100$ mTorr pressure and turbo pumps were initiated at $\sim 40$ mTorr pressure. 
The operating potentials on the start detector were determined by a series of experiments on a $300 \AA$ gold film on silicon sample. Spectra were collected for various voltages on the electrostatic mirror and the foil. The resulting matrix of mirror voltage and foil voltage allowed us to choose the operating condition that provided ample counts and an excellent signal to noise ratio.

The stop detector, located $1.635 \mathrm{~m}$ from the start detector and $1.868 \mathrm{~m}$ from the sample, defined the flight tube's solid angle at $0.33 \mathrm{mstr}$, as shown in figure 5 . The stop detector consisted of two $40 \mathrm{~mm}$ diameter chevron type fast MCP detectors and a conical anode with $50 \mathrm{ohm}$ impedance for electron collection. To reduce the number of stray ions entering the flight tube a primary aperture of $8 \mathrm{~mm}$ diameter was placed 12.7 $\mathrm{cm}$ in front of the start foil.

\subsubsection{Alignment}

Alignment of the spectrometer was carried out by adjusting the height of the flight tube and primary aperture and noting the position where light from a pupil at the center of the stop detector passed through the middle of all the apertures. Due to the many apertures involved, it was essential to have the projectile beam and analysis target positioned on the line-of-sight or focal point of the flight tube. Analysis with scattering of $\mathrm{H}^{+}$from a $300 \AA$ gold film on silicon sample showed that steering the beam away from the focal point caused a considerable decrease in count rate and a degradation in the relative timing resolution. In fact, steering the beam allowed one to "image" the primary aperture by noting count rate and beam position.

With a large primary aperture, this steering could experimentally give the amount of angular spread caused by small angle scattering in the foil. Such an 
experimental determination would be an important check on the angular spread calculated by ion transport codes such as TRIM (see below).

To provide information on the TOF detector's efficiency, a surface barrier detector on a linear feedthrough was placed behind the start detector.

\subsection{Signal processing}

A block diagram of the electronic signal processing from both the start and stop MCP detectors is included in figure 3. In our spectrometer, the MCP anode signals were amplified using a Phillips Model 6954 fast amplifier and fed into an Ortec Model 583 constant fraction discriminator (CFD). The CFD provides better temporal resolution by eliminating amplitude dependent time walks. It accomplishes this task by adding a time-delayed, inverted "copy" pulse to the original pulse. Triggering is then set by the zero crossing of the resultant waveform. This method allows for triggering times which are independent of the size of the original pulse. Due to the fast nature of the MCP signals, it was found that the delay time needed to be held to a minimum. The CFD was therefore set to use its inherit 0.71 ns delay time by shorting together its external delay time inputs. An addition of even $1 \mathrm{~ns}(20.00 \mathrm{~cm})$ in delay time lead to erroneous data and low count rates because the inverted pulse was delayed past the original pulse, leading to a slow, poorly defined zero crossing.

From their respective constant fraction discriminators the signals were fed into the start and stop inputs of a LeCroy Model 4204 time to digital converter (TDC) with 156 ps timing resolution. The data were transferred from the TDC to a LeCroy Model 3588 histogramming memory module prior to being displayed on the monitor of a Sun systems Sparc 10. 
Although the data presented in this paper were collected using equal lengths of cabling for start and stop detectors, figure 3 shows a variation capable of producing even higher count rates. The less than 100\% transmittance of the start detector and beam divergence ensures that there are more start signals than stops. This effect is compensated for in figure 3 by delaying the start signal by some time period and feeding it into the stop of the TDC while the stop detector output is fed directly into the start of the TDC. This reversal of start and stop outputs helps eliminate a significant amount of dead time produced in digitizing the time overflow condition on the TDC which results when a start trigger does not have a corresponding stop. Furthermore, the reversal of start and stop outputs gives particles with higher energy larger digital outputs and provides the aesthetic feel that one is viewing an energy rather than time of flight spectrum. 


\section{TOF Spectrometer Resolution and Efficiency}

\subsection{Electronic Timing Resolution}

The resolution of the timing electronics, $\delta \mathrm{t}_{\mathrm{e}}$, which includes the intrinsic limit of the electronics as well as the energy spread of secondary electrons from the foil, was studied using an Americium source, ${ }^{241} \mathrm{Am}[16]$. The isotopically pure ${ }^{241} \mathrm{Am}$ is an emitter of $\alpha$-particles with energies of $5.486 \mathrm{MeV}(85.2 \%)$ and $5.443 \mathrm{MeV}$ (12.8\%). The high energies involved allow the ${ }^{241} \mathrm{Am}$ to be an excellent source of mono-energetic projectiles with negligible energy straggling after passage through the foil; this is demonstrated by the calculated transmitted energy distribution for $5.486 \mathrm{MeV} \alpha$-particles passing through a $19.4 \mu \mathrm{g} / \mathrm{cm}^{2}$ carbon foil shown in figure 6.

Figure 7 shows the Americium source spectrum, which was collected over a period of 48 hours, in both the time and energy domains. This shows $\delta t_{e}$, determined by the width of the leading edge from $16 \%$ to $84 \%$ of the peak height, to be 361 ps; this gives a relative timing resolution, $\frac{\delta \mathrm{t}}{\mathrm{t}}$, better than $0.36 \%$ (the corresponding FWHM is $465 \mathrm{ps}$ ). The leading edge corresponds to approximately two TDC channels and is comparable to the 396 ps flight time difference expected for the two emitted $\alpha$-particles. A similar analysis of the energy spectrum leading edge gave an energy error, $\delta \mathrm{E}$, of $39.5 \mathrm{keV}$ (a FWHM of $50.7 \mathrm{keV}$ ) comparable to the $43 \mathrm{keV}$ energy difference for the two predominant decay species. Thus, since the energy resolution of the spectrometer is on the order of the separation between the two Americium source peaks, the less intense peak at lower energy appears as a shoulder next to the more intense peak.

Deconvolution of the electronic timing resolution, $\delta \mathrm{t}_{\mathrm{e}}$, was accomplished by using a Stanford Research Systems Inc. Model DG535 high resolution pulser. The FWHM of the TOF peak resulting from the pulser's NIM pulse, 50 ps RMS jitter, and delayed NIM 
pulse feeding the start and stop constant fraction discriminators, respectively, gave an electronic resolution limit of $238 \mathrm{ps}$. As a result, the timing error for the secondary electron energy spread from the foil was determined to be $270 \mathrm{ps}$.

\subsection{Total Relative Timing Resolution}

In this section, we analyze and determine how the total relative timing error is affected by the many design parameters of a TOF spectrometer. From equation 9 , the timing error for a particle of mass $m$ is found to be:

$$
\delta \mathrm{t}=\sqrt{\left(\frac{\partial \mathrm{t}}{\partial \mathrm{E}} \delta \mathrm{E}\right)^{2}+\left(\frac{\partial \mathrm{t}}{\partial \mathrm{L}} \delta \mathrm{L}\right)^{2}+\delta \mathrm{t}_{\mathrm{e}}^{2}} .
$$

The length error is much smaller than the other two errors provided the angular divergence of the beam is minimized. Therefore, with the use of equation 11 , the total relative timing error becomes:

$$
\frac{\partial t}{t}=\sqrt{\left(\frac{1}{2} \frac{\partial E}{E}\right)^{2}+\left(\frac{\delta t_{e}}{t}\right)^{2}} .
$$

The total energy error, $\delta \mathrm{E}=\delta \mathrm{E}_{\mathrm{loss}}$, results from energy losses associated with the accelerator ripple (AR), energy straggling using Bohr's theory (FSB) upon passing through the foil, and a 10\% nonuniformity factor for the carbon foil (NU). Summed in quadrature, these errors lead to a contribution to the relative timing error as follows:

$$
\left(\frac{\delta \mathrm{t}}{\mathrm{t}}\right)_{\delta \mathrm{E}_{\text {loss }}}=\frac{1}{2} \frac{\delta \mathrm{E}_{\text {loss }}}{\mathrm{E}}=\frac{1}{2} \frac{\left[\left(\delta \mathrm{E}_{\mathrm{AR}}\right)^{2}+\left(\delta \mathrm{E}_{\mathrm{FSB}}\right)^{2}+\left(\delta \mathrm{E}_{\mathrm{NU}}\right)^{2}\right]^{1 / 2}}{\mathrm{E}} .
$$

A graphical error analysis is shown in figure 8 for $\mathrm{H}^{+}$and a free flight path of $1.635 \mathrm{~m}$ [17]. The first graph shows the time of flight, as calculated by equation 9 , for $\mathrm{H}^{+}$ 
at various energies and a free flight path length of $1.635 \mathrm{~m}$. Figure 8-b graphs the relative timing error resulting from the total energy loss error, $\delta \mathrm{E}_{\text {loss }}$, at various energies. Figure 8-c indicates the relative timing error at various energies due to the electronic timing error, $\delta t_{e}$, determined from the Americium spectrum. Finally, figure 8-d shows the results of summing both $b$ and $c$ in quadrature according to equation 19. For this projectile and path length, the total relative timing error for all projectile energies simulated is due primarily to the total energy loss error, $\delta E_{l o s s}$, with the major contributor being the accelerator ripple, AR.

The Modular design of the flight tube allows for variation in the free flight path length and, in figure 9, calculations are graphed for a free flight path length of $0.708 \mathrm{~m}$ to compare with those in figure 8 . The total energy loss error results are similar since conditions through the foil have not changed. However, due to the shorter flight path length, and correspondingly shorter flight times, the electronic timing error, $\delta t_{e}$, becomes much more substantial; it increases by more than a factor of two. This timing error increase reveals itself in figure 9- $d$ where a local minimum appears. The minimum represents a cross-over point. That is, for projectile energies to the left of this minimum the total energy loss error, $\delta \mathrm{E}_{\text {loss }}$, is the major contributor to the total relative timing error. On the other hand, for projectile energies to the right of this minimum, the total relative timing error is due almost entirely to the electronic timing error, $\delta t_{e}$.

The dependence of the spectrometer's total relative timing error on the total energy loss error, $\delta \mathrm{E}_{\text {loss }}$, and the electronic timing error, $\delta \mathrm{t}_{\mathrm{e}}$, is further illustrated in figure 10 where a heavier projectile, nitrogen, and a free flight path length of $0.708 \mathrm{~m}$ are used in the calculation. The heavier mass results in longer flight times and makes the electronic timing error, $\delta t_{e}$, less significant as compared to the total energy loss error, $\delta \mathrm{E}_{\text {loss }}$. For the larger atomic number projectile, the total energy loss error, $\delta \mathrm{E}_{\text {loss }}$, has increased due to increased energy straggling and an increased energy loss variation from 
foil nonuniformity arising from a larger $\mathrm{dE} / \mathrm{d} x$ value. Even for the relatively short flight path length, the total relative timing error is due entirely to the total energy loss error, $\delta \mathrm{E}_{\mathrm{loss}}$, for all projectile energies simulated.

These results demonstrate the difficulties of achieving greater kinematic(mass) resolution with the use of heavy ions. Medium energies and long flight tubes, $\sim 2 \mathrm{~m}$, work well with light ions (the low radial divergence angle helps preserve count rates). However, for nitrogen ions or any other heavy ion projectile, the resolution is set by straggling and foil nonuniformity in the start detector. Therefore, the way to minimize the effects of energy straggling and angular divergence is to use thin foils, higher energies ( $>1 \mathrm{MeV})$ and shorter flight paths. 


\section{Start Detector Foil Characteristics}

\subsection{Energy and Spatial Spread of Transmitted Projectiles}

TRIM[18] calculations were performed in order to characterize the energy and spatial (lateral and angular) spread of projectiles transmitted through the foil used in our start detector. With PC based TRIM 92 (ver 92.12), simulations were run for $500 \mathrm{keV} \mathrm{H}^{+}$, $\mathrm{He}^{+}, \mathrm{N}^{+}$, and $\mathrm{Ne}^{+}$using ten thousand ions passing through a $19.4 \mu \mathrm{g} / \mathrm{cm}^{2}$ thick carbon foil. The results are presented in figures $11-14$.

As seen in the graph of figure 11, the calculated transmitted particle energies for $\mathrm{H}^{+}$and $\mathrm{He}^{+}$have a Gaussian distribution as predicted by Bohr's theory. The calculated total stopping powers through the foil for these ions are $7 \mathrm{keV}$ and $39.6 \mathrm{keV}$, respectively. The FWHM values for the Gaussian fit to the histogrammed energy distributions of $3.7 \mathrm{keV}$ and $5.9 \mathrm{keV}$ for $\mathrm{H}^{+}$and $\mathrm{He}^{+}$, respectively, give an indication of the degree of energy straggling.

The degree of radial lateral and radial angular spread between the entrance and exit points on the foil for $500 \mathrm{keV} \mathrm{H}{ }^{+}$ions can be seen in figure 12. In figure 12-a the probability for a $\mathrm{H}^{+}$ion to experience a radial lateral deflection between $\mathrm{r}$ and $\mathrm{r}+\mathrm{dr}$ upon passage through the foil is histogrammed. Figure 12-b shows the corresponding probability density, i.e., the probability for deflection into an annular region with a radius $r$ and width $d r$, divided by the area of the region $(2 \pi r d r)$. Likewise, in figure 12-c the probability as a function of radial angle is histogrammed, while figure 12-d shows the corresponding probability density.

Simple geometric considerations, which are presented in figure 5, show that in order for an ion to hit the stop detector in our spectrometer, the maximum radial angle, 
$\theta_{\max }$, must be less than $0.7^{\circ}$. Figure $12-\mathrm{c}$ shows that the majority of $\mathrm{H}^{+}$ions are deflected by less than this amount and would therefore be counted.

For comparison, figure 13 graphs the probability histogram of the transmitted energy for $\mathrm{N}^{+}$and $\mathrm{Ne}^{+}$at $500 \mathrm{keV}$. Unlike $\mathrm{H}^{+}$and $\mathrm{He}^{+}$, all $\mathrm{N}^{+}$and $\mathrm{Ne}^{+}$ions suffer extensive stopping loss with the energy distribution including values from zero to a maximum cut off energy. The TRIM calculated stopping powers of $88.3 \mathrm{keV}$ and 80.1 $\mathrm{keV}$ for $\mathrm{N}^{+}$and $\mathrm{Ne}^{+}$ions, respectively, clearly show the increased susceptibility of peak broadening for heavy ions in this type of start detector.

Furthermore, the radial lateral and corresponding radial angular spread for 500 $\mathrm{keV} \mathrm{N}^{+}$, shown in figure 14, is so pronounced - they are a factor of ten more than the corresponding values for $500 \mathrm{keV} \mathrm{H}^{+}$- that most ions would miss the stop detector in our spectrometer altogether! In addition, this kind of divergence has been known to cause recoiling of light species from the walls of the flight tube resulting in misleading peaks at fast times[15]. We observed this feature in a spectrum, which is not shown, of $500 \mathrm{keV} \mathrm{N}^{+}$scattered from a $300 \AA$ gold film on silicon sample. In this spectrum, the main gold peak was barely above a background which consisted of counts at all time intervals.

\subsection{Influence of Foil Thickness}

Additional TRIM simulations were made to determine the advantages and disadvantages of using a foil with a different foil thickness. The calculated energy and angular spreads for both $500 \mathrm{keV} \mathrm{H}{ }^{+}$and $\mathrm{N}^{+}$passing through $5.0 \mu \mathrm{g} / \mathrm{cm}^{2}$ and 80.0 $\mu \mathrm{g} / \mathrm{cm}^{2}$ thick carbon foils - respectively four times thinner and four times thicker than the foil used in our spectrometer - are shown in figures 15 and 16, respectively. 
For $\mathrm{H}^{+}$(figure 15), a Gaussian distribution of ion energies emerges from both foil thicknesses. In addition, the degree of radial angular spread scales with the square root of the foil thickness. Thus, while all the projectiles transmitted through the $5.0 \mu \mathrm{g} / \mathrm{cm}^{2}$ foil would hit the stop detector, the number detected after passing through the 80 $\mu \mathrm{g} / \mathrm{cm}^{2}$ foil would be reduced to $\sim 75 \%$ due to the larger radial angular spread. It should be noted however, that while the $5.0 \mu \mathrm{g} / \mathrm{cm}^{2}$ foil offers a low energy error contribution from energy straggling, a study by J. Girard and $\mathrm{M}$. Bolore with ${ }^{252} \mathrm{Cf}$ fission fragments showed that the secondary electron yield decreases by as much as $\sim 30 \%$ for foil thicknesses below $\sim 20 \mu \mathrm{g} / \mathrm{cm}^{2}$, resulting in lower spectrometer efficiency[1, 19].

The results for $\mathrm{N}^{+}$(figure 16) show considerable energy straggling with particles emerging with a wide range of energies. The degree of angular spread did not show a simple scaling behavior and was substantial with all the thicknesses simulated. Even with the $5.0 \mu \mathrm{g} / \mathrm{cm}^{2}$ foil, only half the transmitted ions would be detected with our 1.635 $\mathrm{m}$ flight tube. Detection of the remaining ions emerging from the foil would require a shorter flight path and/or a larger diameter for the stop detector.

These calculations show that the advantage of achieving better mass resolution by use of heavy ions is offset by energy straggling in the foil for energies below $1 \mathrm{MeV}$. Furthermore, the increased angular spread contributes to substantial count rate reductions and lower signal to noise ratios.

\subsection{TRIM Precautions}

Since the degree of energy straggling, $\Omega$, is an important parameter in determining the energy resolution for the medium energies of interest in this paper, we 
have examined the relative appropriateness of applying various methods of $\Omega$ calculation to the problem of projectiles passing through very thin films.

Bohr's straggling theory is simple to use but has certain inadequacies. It is energy-independent and, since it relies on the high probability of projectiles encountering numerous small-energy-transfer single collisions (a process that leads to Gaussian energy loss statistics [20]), it gives an unrealistic energy loss distribution (the finite but low probability of single collisions with high-energy-transfer adds a nonGaussian component to the distribution of transmitted energies $[20,21])$.

Meanwhile, the large path length used in TRIM limits the number of interactions encountered by a projectile as it passes through very thin foils. Thus, for the problem of interest, Trim does not produce a realistic functional form for energy straggling. In addition, experimentation by D.H. Morse has indicated that TRIM produces a low value estimate for the degree of radial angular spread for ions passing through thin foils[22].

To overcome the deficiencies of the Bohr and TRIM calculations, a modified TRIM code has been written[23] which takes into account foil thickness and projectile energy in determining the energy straggle[20,24].

Table 1. Results of various calculations to determine energy straggle.

\begin{tabular}{lccc|ccc}
\hline & \multicolumn{3}{c|}{$500 \mathrm{keV} \mathrm{H}^{+}$} & \multicolumn{3}{c}{$500 \mathrm{keV} \mathrm{N}^{+}$} \\
\hline & $\begin{array}{c}5.0 \\
\mu \mathrm{g} / \mathrm{cm}^{2}\end{array}$ & $\begin{array}{c}19.4 \\
\mu \mathrm{g} / \mathrm{cm}^{2}\end{array}$ & $\begin{array}{c}80.0 \\
\mu \mathrm{g} / \mathrm{cm}^{2}\end{array}$ & $\begin{array}{c}5.0 \\
\mu \mathrm{g} / \mathrm{cm}^{2}\end{array}$ & $\begin{array}{c}19.4 \\
\mu \mathrm{g} / \mathrm{cm}^{2}\end{array}$ & $\begin{array}{c}80.0 \\
\mu \mathrm{g} / \mathrm{cm}^{2}\end{array}$ \\
\hline$\Omega_{\text {Bohr }}$ & $0.62 \mathrm{keV}$ & 1.23 & 2.50 & 4.39 & 8.64 & 17.55 \\
$\Omega_{\text {TRIM }}$ & 0.63 & 1.29 & 2.54 & 3.69 & 10.56 & 16.73 \\
$\Omega_{\text {MTRM }}$ & 0.47 & 0.93 & 1.90 & 6.01 & 11.61 & 21.62 \\
$\Omega_{\text {GF }}$ & 0.80 & 1.57 & 3.13 & 0.63 & 1.23 & 2.71 \\
\hline
\end{tabular}


A comparison of these methods of calculation for the degree of energy straggle, $\Omega$, is shown in table 1. This table shows the values from Bohr's theory, $\Omega_{\mathrm{Bohr}}$, the original TRIM code, $\Omega_{\mathrm{TRIM}}$, and the modified TRIM code, $\Omega_{\mathrm{MTRIM}}$ for $500 \mathrm{keV} \mathrm{H}^{+}$and $\mathrm{N}^{+}$ions passing through $5.0,19.4$, and $80.0 \mu \mathrm{g} / \mathrm{cm}^{2}$ thick carbon foils. The $\Omega_{\text {TRIM }}$ values were obtained from the second moment of the simulated transmitted energy distributions shown in figures 11 - 16 while the $\Omega_{\text {MTRIM }}$ values were obtained from similar simulations. The TRIM transmitted energy distributions were fit to Gaussians in order to provide a measure of their proximity to Gaussian shape [17]. The standard deviations for these fits, $\Omega_{\mathrm{GF}}$ are included in table 1.

The results show that for $\mathrm{H}^{+}$, all three values, $\Omega_{\mathrm{Bohr}}, \Omega_{\mathrm{TRM}}, \Omega_{\mathrm{MTRIM}}$, are similar for each foil thickness studied. Furthermore, $\Omega_{\mathrm{GF}}$ and $\Omega_{\mathrm{TRIM}}$ were in reasonable agreement for each foil, indicating that the transmitted energy distributions for $500 \mathrm{keV} \mathrm{H} \mathrm{H}^{+}$are representative of a Gaussian distribution.

For $\mathrm{N}^{+}, \Omega_{\mathrm{TRIM}}$ is close to $\Omega_{\mathrm{MTRIM}}$ for the $19.4 \mu \mathrm{g} / \mathrm{cm}^{2}$ thick foil. On the other hand, TRIM underestimated the energy straggling for the other foil thicknesses and also failed to produce a square root dependence for energy straggling on foil thickness. In addition, $\Omega_{\mathrm{GF}}$ and $\Omega_{\mathrm{TRIM}}$ are distinctly different due to the very non-Gaussian asymmetric distribution of ion energies emerging from the foil. More importantly, the modified calculations, $\Omega_{\mathrm{MTRIM}}$, are larger than $\Omega_{\mathrm{Bohr}}$ due to the simplifications in Bohr's theory as mentioned above. This means that for heavy ions, the resolution is poorer than that predicted by equation 19 . 


\section{Experimentation}

\subsection{Performance and Efficiency}

The first scattering experiments were performed with $500 \mathrm{keV} \mathrm{H}^{+}$scattering from a $300 \AA$ gold film on silicon sample with a beam slit size of $2 \mathrm{~mm} \times 3 \mathrm{~mm}$. A TOF spectrum for three minutes of data acquisition using a $300 \mathrm{nA}$ beam is displayed in both the time and energy domains in figure 17. It shows a sharp peak associated with the 300 $\AA$ thick gold layer and a continuum of scattered energies associated with the silicon substrate. An energy error, $\delta \mathrm{E}$, of $\sim 3.5 \mathrm{keV}$ - corresponding to a relative energy error of $0.72 \%$ - was obtained from leading edge analysis. The resolution for the TOF detector is thus three to four times better than that obtainable with a surface barrier detector. A similar leading edge analysis gives a timing error, $\delta \mathrm{t}$, of $610 \mathrm{ps}$ - corresponding to a relative timing resolution of $0.36 \%$ - which is approximately $\sim 1.7$ times that measured for the Americium source. Since the increase is due mainly to accelerator ripple, a more stable accelerator would give spectra with timing errors comparable to those of the Americium source and an energy resolution approximately five to six times that obtainable with a surface barrier detector. A $34 \%$ detection efficiency for this TOF spectrometer was determined by comparing this spectrum to one taken under the same conditions with a surface barrier detector (assumed to have 100\% detection efficiency).

\subsection{Resolution}

A second sample was fabricated to further test the spectrometer resolution. It consisted of $300 \AA$ of gold grown on top of $300 \AA$ of palladium deposited on glass. The $\mathrm{Au}-\mathrm{Pd}$ was etched to form a square net of metal and a matrix of underlying glass which revealed the $500 \mathrm{keV} \mathrm{H} \mathrm{H}^{+}$beam position on the sample through fluorescence. The 
spectrometer's total relative timing error of $0.36 \%$ for $500 \mathrm{keV} \mathrm{H}^{+}$, as graphed in figure 8$\mathrm{d}$, is slightly better than the $0.43 \%$ value needed to resolve the Au and Pd masses ( value equal to half the relative difference in the two kinematic factors). So, ideally the two peaks should be resolved in our spectrometer. Figure 18 shows a TOF spectrum for this sample in both the time and energy domains. The Au peak in this spectrum has a sharp leading edge, a height determined by the Au scattering cross-section, and a width determined by the Au film thickness[25]. Since the ion loses energy as it passes through the $\mathrm{Au}$ (at the rate of $\left.(\mathrm{dE} / \mathrm{d} x)_{\mathrm{Au}}=16.9 \mathrm{eV} / \AA\right)$, the scattering cross-section increases with depth and the height of the Au peak increases with decreasing energy. The leading edge of the Pd peak is shifted from the Au peak's leading edge by energy loss from traversing the $\mathrm{Au}$ and by the difference in kinematic factors. The width of the Pd peak is comparable to that of the Au since $(\mathrm{dE} / \mathrm{d} x)_{\mathrm{Pd}}=16.8 \mathrm{eV} / \AA$, but its height is smaller due to a smaller cross-section. The two peaks are not fully resolved - the Pd peak appears as a shoulder to the left of the Au peak - due to energy straggling $\left(\Omega_{\mathrm{TRM}-\mathrm{Au}}=3.1 \mathrm{keV}\right)$ and nonuniformity in the Au film. The Pd peak's broad trailing edge is a further result of these effects together with straggling and nonuniformity of the $\mathrm{Pd}$ film $\left(\Omega_{\mathrm{TRM} \cdot \mathrm{Pd}}=3.90\right.$ $\mathrm{keV})$. 


\section{Conclusion and Future Work}

\subsection{Report Summary}

The are many design parameters involved in the construction of a TOF spectrometer and some must be compromised. This report describes methods to optimize the performance of a TOF spectrometer for specialized experiments. Once the $\delta \mathrm{K}_{\mathrm{p}}$ of the masses to be resolved is determined, calculations like those presented in figures 8-10 are used to determine the effect of scattering angle, projectile energy, projectile mass, free flight path length, and foil thickness on the resolution.

The scattering angle, which determines the difference in scattering factors for a projectile and two target elements and thus the timing resolution, must be optimized but not at the expense of a small scattering cross-section. It would be ideal to use $180^{\circ}$ scattering; however, the reduction in cross-section and solid angle limits the count rate at this angle[1] so values between $135^{\circ}$ and $175^{\circ}$ are usually chosen.

It is only practical to use light ions for energies below $1 \mathrm{MeV}$ since the straggling in the foil will be too large for heavy ions. However, since light ions travel at relatively high speeds, long flight path lengths are required in order to keep the relative electronic timing error, $\frac{\delta t_{e}}{t}$, small. Fortunately, the fact that these projectiles have a low radial angle divergence allows for flight lengths that are in excess of two meters.

The use of heavy ions becomes practical at higher energies $(\mathrm{E}>1 \mathrm{MeV})$ where the relative energy loss error, $\frac{\delta \mathrm{E}_{\text {loss }}}{\mathrm{E}}$, can be kept small compared to the total relative timing error needed for the desired mass resolution. Of special concern in this application is the flight path length. It should be long enough for the relative electronic timing error, $\frac{\delta t_{e}}{t}$, to be comparable to the relative energy loss error, $\frac{\delta \mathrm{E}_{\text {loss }}}{\mathrm{E}}$. However, it should also be 
short enough, and the stop detector diameter large enough, to provide acceptable count rates which can be diminished due to the large radial angle divergence of heavy ions. Also, this divergence leads to various arrival times for identically scattered particles; this error must be included in the total timing error, $\delta \mathrm{t}$ (see equation 18). Furthermore, to prevent recoils from the flight tube walls, baffles should be installed.

From our simulated dynamics, a $5.0 \mu \mathrm{g} / \mathrm{cm}^{2}$ thick foil offers superior performance over other foil thicknesses and should be used when high energy resolution is mandated. However, when the secondary electron emission yield (count rate) and the resilience factor are taken into account, thicker foils are required. The $19.4 \mu \mathrm{g} / \mathrm{cm}^{2}$ thick foil used in our detector offers a modest increase in energy straggling and a comparable radial angle spread when $\mathrm{H}^{+}$ions are used.

Greater count rates and improved spectrum quality can be achieved by enhancing secondary electron emission. To improve efficiency, elements other than carbon should be tried as an emission source of secondary electrons. For instance, J. Girard and M. Bolore have tried aluminum, gold and magnesium-oxide foils. The magnesium-oxide foils had the greatest secondary electron emission which was five or six times that of carbon. However, the quality and nonuniformity of magnesium-oxide foils result in increased energy straggling[19]. Nevertheless, a 150\% improvement in start detector efficiency was reported by M.L. Roberts[26] using a thin film of magnesium-oxide evaporated onto the back of a carbon foil. Likewise, a thin film of cesium on carbon may also improve the secondary electron yield[27,28]. These results are promising and should prompt further experimental investigation into materials capable of producing increased secondary electron emission without increased projectile energy straggle[19, 29]. 


\subsection{Future Experiments and Designs}

We recommend the following future work:

1. The angular spread for ions through the foil should be measured and compared to TRIM simulations. A large primary aperture would allow for an experimental determination of the ion angular spread by noting count rates for various beam positions on the sample. This measurement however, may require baffles in the beam line to prevent spurious effects resulting from stray ions colliding with the flight tube wall.

2. A direct measure of the energy straggling in carbon foils should also be made. One easy way to accomplish this task is to float foils of known thickness onto standard samples. By probing parts of the sample with and without the foil, accurate differences can be measured leading to a determination of straggling.

3. One promising approach for improving the timing resolution is to use channel plates that can be driven at higher voltages thereby greatly shortening the pulse rise time. Since the time walk associated with different size pulses is inversely proportional to the rise time, these channel plates help to eliminate the need for constant fraction discriminators.

4. The start detector should be refitted with finer mesh or wire grids. This refitting would allow for more homogeneous and contained electric fields resulting in a smaller spread for the secondary electron flight times and hence, an improvement of the timing error at a small sacrifice of transmissivity. Furthermore, electron trajectory codes and estimates should be used to explore the role of electron flight time variation on resolution. 
5. For future design changes it is proposed to change the scattering angle to a value of $135^{\circ}$ which would allow, for example, the separation of gallium and arsenic. Also, the new flight tube should have variable length control by incorporating the use of a stop detector seated at the end of a moveable bellows. An in situ variable length flight tube would allow different projectile masses to be used without a need for venting a chamber in order to vary the flight tube length. Furthermore, an in situ variable length flight tube would be valuable for direct recoil TOF measurements. The spread in mass and energy for the recoiled particles can be large, and an in situ variable length flight tube allows the resolution to be maximized for a particular mass and energy of interest. 


\section{REFERENCES}

[1] M. DÔbeli, P.C. Haubert, R.P. Livi, S.J. Spicklemire, D.L. Weathers and T.A. Tombrello, Nucl. Intstr. and Meth. B47 (1990) 148

[2] M.H. Mendenhall and R.A. Weller, Nucl. Intstr. and Meth. B40 (1989) 1239

[3] W.C. Wiley, and I.H. Mclaren, Rev of Sci. Instr. 26 (1958) 1150

[4] E.C. Finch, Nucl. Intstr. and Meth. 113 (1973) 41

[5] A. Chevarier, N. Chevarier, and S. Chiodelli, Nucl. Intstr. and Meth. 189 (1981) 525

[6] R. Stanley Williams, Quantitative Intensity Analysis of Low Energy Scattering and Recoiling from Crystal Surfaces To be published.

[7] W. Eckstein and R. Bastasz, Nucl. Intstr. and Meth. B29 (1988) 603

[8] E. Taglauer and W. Heiland, Appl. Phys. 9 (1976) 261

[9] A. Chevarier and N. Chevarier, Nucl. Intstr. and Meth. 218 (1983) 1

[10] M. Aono, C. Oshima, S. Zaima, S. Otani and Y. Ishizawa, Jpn. J. Appl. Phys. 20 (1981) L829

[11] A.G.J. DeWit, R.P.N. Bronckers and J.M. Fluit, Surf, Sci. 82 (1979) 177

[12] N. Bohr, Philos. Mag 30 (1915) 581

[13] G. D'Erasmo, V. Paticchio, and A. Pantaleo, Nucl. Intstr. and Meth. 193 (1985) 91

[14] W. Starzecki, A.M. Stefanini, S. Lunardi, and C. Signorini, Nucl. Intstr. and Meth. 193 (1982) 499

[15] R. M. Charatan, R.S. Daley, S. Chaudhury, S.J. Anz, R. S. Williams, and C. C. Chang, Nucl. Intstr. and Meth. B73 (1993) 570

[16] M.H. Mendenhall and R.A. Weller, Nucl. Intstr. and Meth. B47 (1990) 193

[17] The graphical error analyses of figures 8-10 and the Gaussian curve fits of table 1 were obtained with macros written for the Macintosh ${ }^{\mathrm{Tu}}$ application, IGOR $^{\mathrm{tm}}$.

[18] J.P. Biersack and L.D. Haggmark, Nucl. Intstr. and Meth. 174 (1980) 257

[19] J. Girard and M. Bolore, Nucl. Intstr. and Meth. 140 (1977) 279 
[20] G.H. Bauer, A.J. Antolak, A.E. Pontau, D.H. Morse, D.W. Heikkinen, and I.D. Proctor, Nucl. Intstr. and Meth. B43 (1989) 497

[21] L. Landau, J. Phys. (USSR) 8 (4) (1944) 201

[22] D.H. Morse, Sandia National Laboratories, Livermore CA 94551 - USA. Personal Correspondences.

[23] A.J. Antolak, Sandia National Laboratories, Livermore CA 94551 - USA. Personal Correspondences.

[24] A.J. Antolak, Nucl.Intstr. and Meth. B30 (1988) 182

[25] L.C. Feldman Fundamental of surface and thin film analysis North Holland 1986

[26] M.L. Roberts, D.W. Heikkinen, I.D. Proctor, A.E. Pontau, G.T. Olona, T.E. Felter, D.H. Morse, and B.V. Hess. Nucl. Intstr. and Meth. B77 (1993) 225

[27] Haefer et al., Z Phys. 116 (1940) 604

[28] Macaulay et al., Appl. Phys. Lett. 61 (1992) 997

[29] A.E. Pontau, A.J. Antolak, and D.H. Morse, Nucl. Intstr. and Meth. B45 (1990) 503

Macintosh is a trade mark of Apple Computer Company, Cupertino, CA. IGOR is a trade mark of WaveMetrics, Lake Oswego, OR. 


\section{FIGURES}

Figure 1. Binary collision diagram for laboratory coordinate system.

Figure 2. (a) The difference in the kinematic factors for two isotopes of uranium as a function of projectile mass for various scattering angles.

(b) Corresponding relative difference in the kinematic factors normalized to the $180^{\circ}$ scattering case. The mass resolution - the relative change in the kinematic factor, $\frac{\delta \mathrm{K}_{\mathrm{p}}}{\mathrm{K}_{\mathrm{p}}}$, per change in the target mass, $\delta \mathrm{M}_{\mathrm{T}}$ - is greatest at a scattering angle of $180^{\circ}$.

(c) The difference in the kinematic factors as a function of scattering angle for various projectile masses.

(d) Corresponding relative difference in kinematic factors. For a constant scattering angle, an optimal mass resolution is obtained when the projectile and target masses are about equal.

Figure 3. A schematic of our TOF spectrometer showing the start and stop detectors and a block diagram of the electronics.

Figure 4. Schematic of the TOF start detector.

Figure 5. (a) The relevant lengths and solid angles involved in our TOF spectrometer . (b) An illustration of the maximum radial angle a trajectory may posses and still contribute to a stop signal.

Figure 6. Simulated probability histogram of transmitted energy for $5.486 \mathrm{MeV} \mathrm{He}^{++}$ ions (as emitted from a ${ }^{241} \mathrm{Am}$ source) passing through a $19.4 \mu \mathrm{g} / \mathrm{cm}^{2}$ carbon foil. The simulations were run with TRIM using 10,000 ions. 
Figure 7. A TOF spectrum in both the time and energy domains from an Americium source. The width of the leading edge form $16 \%$ to $84 \%$ of the TOF peak established the electronic timing error, $\delta \mathrm{t}_{\mathrm{e}}$, at $361 \mathrm{ps}$.

Figure 8. Graphical analysis of a TOF spectrometer's total relative timing error for $\mathrm{H}^{+}$ and a free flight path length of $1.635 \mathrm{~m}$.

(a) The time of flight at various energies.

(b) The relative timing error due to the total energy loss error, $\delta \mathrm{E}_{\text {loss }}$, for various free flight energies.

(c) The relative timing error due to the electronic timing error, $\delta t_{e}$, for various free flight energies.

(d) The results of (b) and (c) summed in quadrature to give the total relative timing error for the spectrometer.

Figure 9. Graphical analysis, similar to that in figure 8, of a TOF spectrometer's total relative timing error for $\mathrm{H}^{+}$and a free flight path length of $0.708 \mathrm{~m}$.

Figure 10. Graphical analysis, similar to that in figure 8, of a TOF spectrometer's total relative timing error for $\mathrm{N}^{+}$and a free flight path length of $0.708 \mathrm{~m}$.

Figure 11. Simulated probability histograms of transmitted energy for $500 \mathrm{keV} \mathrm{H}^{+}$and $\mathrm{He}^{+}$passing through a $19.4 \mu \mathrm{g} / \mathrm{cm}^{2}$ carbon foil. The simulations were run with TRIM using 10,000 ions.

Figure 12. Simulated quantities for $500 \mathrm{keV} \mathrm{H}^{+}$passing through a $19.4 \mu \mathrm{g} / \mathrm{cm}^{2}$ carbon foil: (a) probability for a lateral deflection; (b) corresponding probability density; (c) probability for a deflection by listed polar angle; and (d) 
corresponding probability density. Note that in our spectrometer, for an ion to hit the stop detector ( $1.635 \mathrm{~m}$ away from the foil), the maximum radial angle, $\theta_{\max }$, must be less than $0.7^{\circ}$. The simulations were run with TRIM using 10,000 ions.

Figure 13. Simulated probability histograms of transmitted energy for $500 \mathrm{keV} \mathrm{N}+$ and $\mathrm{Ne}^{+}$passing through a $19.4 \mu \mathrm{g} / \mathrm{cm}^{2}$ carbon foil. The simulations were run with TRIM using 10,000 ions.

Figure 14. The same simulated quantities as in figure 12 but for $500 \mathrm{keV} \mathrm{N}^{+}$passing through a $19.4 \mu \mathrm{g} / \mathrm{cm}^{2}$ carbon foil. Again, note that in our spectrometer, for an ion to hit the stop detector ( $1.635 \mathrm{~m}$ away from the foil), the maximum radial angle, $\theta_{\max }$, must be less than $0.7^{\circ}$.

Figure 15. Simulated quantities for $500 \mathrm{keV} \mathrm{H}^{+}$passing through a $5.0 \mu \mathrm{g} / \mathrm{cm}^{2}$ carbon foil: (a) probability histogram of transmitted energy and (b) corresponding probability for a deflection by listed polar angle. Simulated quantities for $500 \mathrm{keV} \mathrm{H} \mathrm{H}^{+}$passing through a $80.0 \mu \mathrm{g} / \mathrm{cm}^{2}$ carbon foil: (c) probability histogram of transmitted energy and (d) corresponding probability for a deflection by listed polar angle.

Figure 16. The same simulated quantities as in figure 15 but for $500 \mathrm{keV} \mathrm{N}^{+}$passing through the $5.0 \mu \mathrm{g} / \mathrm{cm}^{2}$ and $80 \mu \mathrm{g} / \mathrm{cm}^{2}$ carbon foils. Again, note that in our spectrometer, for an ion to hit the stop detector (1.635 $\mathrm{m}$ away from the foil), the maximum radial angle, $\theta_{\max }$, must be less than $0.7^{\circ}$.

Figure 17. A TOF spectrum in both the time and energy domains for $500 \mathrm{keV} \mathrm{H}^{+}$ scattering from a $300 \AA$ gold film on silicon sample. The scattering angle is $90^{\circ}$. 
Figure 18. A TOF spectrum in both the time and energy domains for $500 \mathrm{keV} \mathrm{H}^{+}$ scattering from a $300 \AA$ gold on $300 \AA$ palladium on glass sample. The scattering angle is $90^{\circ}$. 


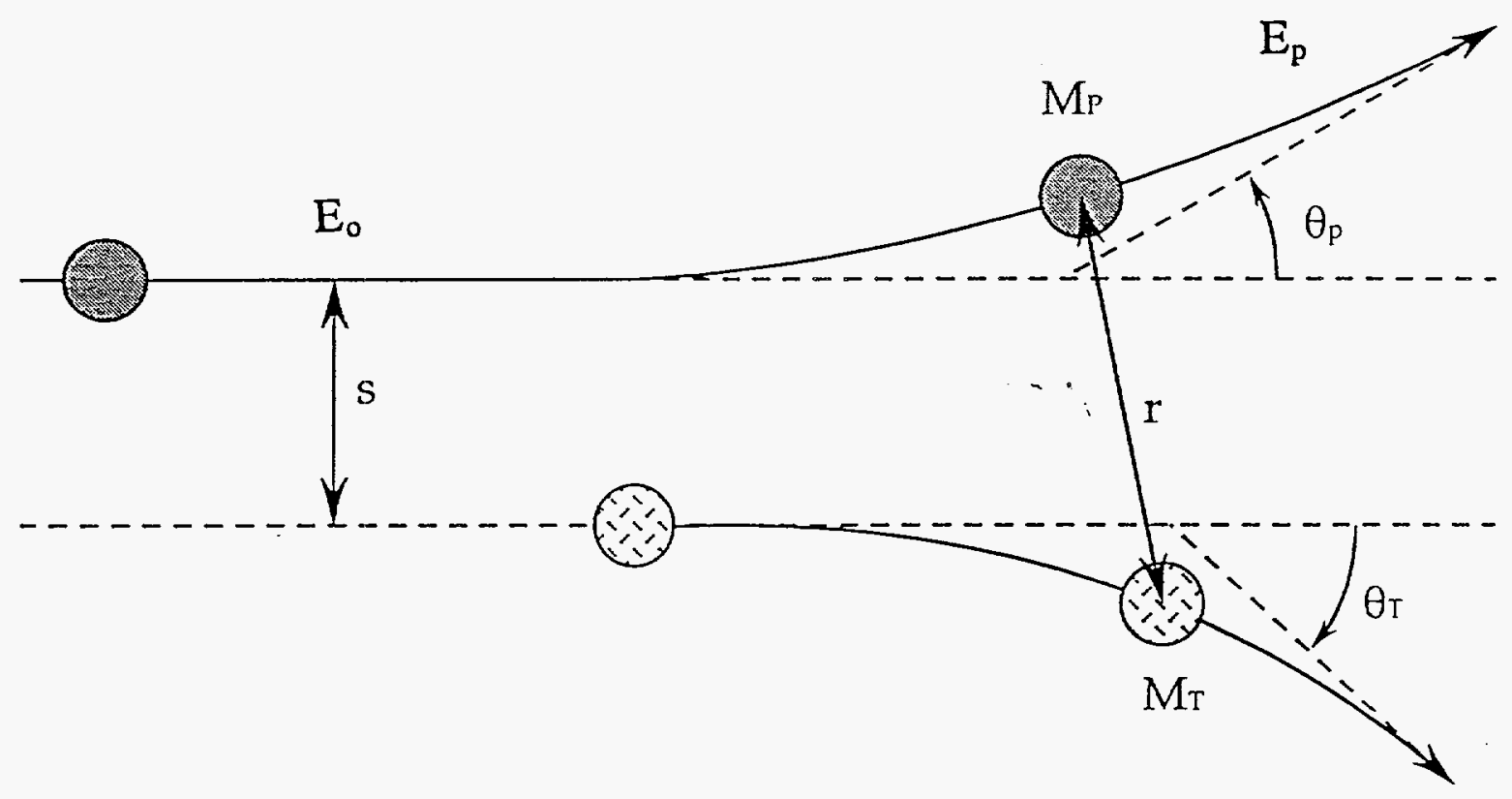

Figure 1 

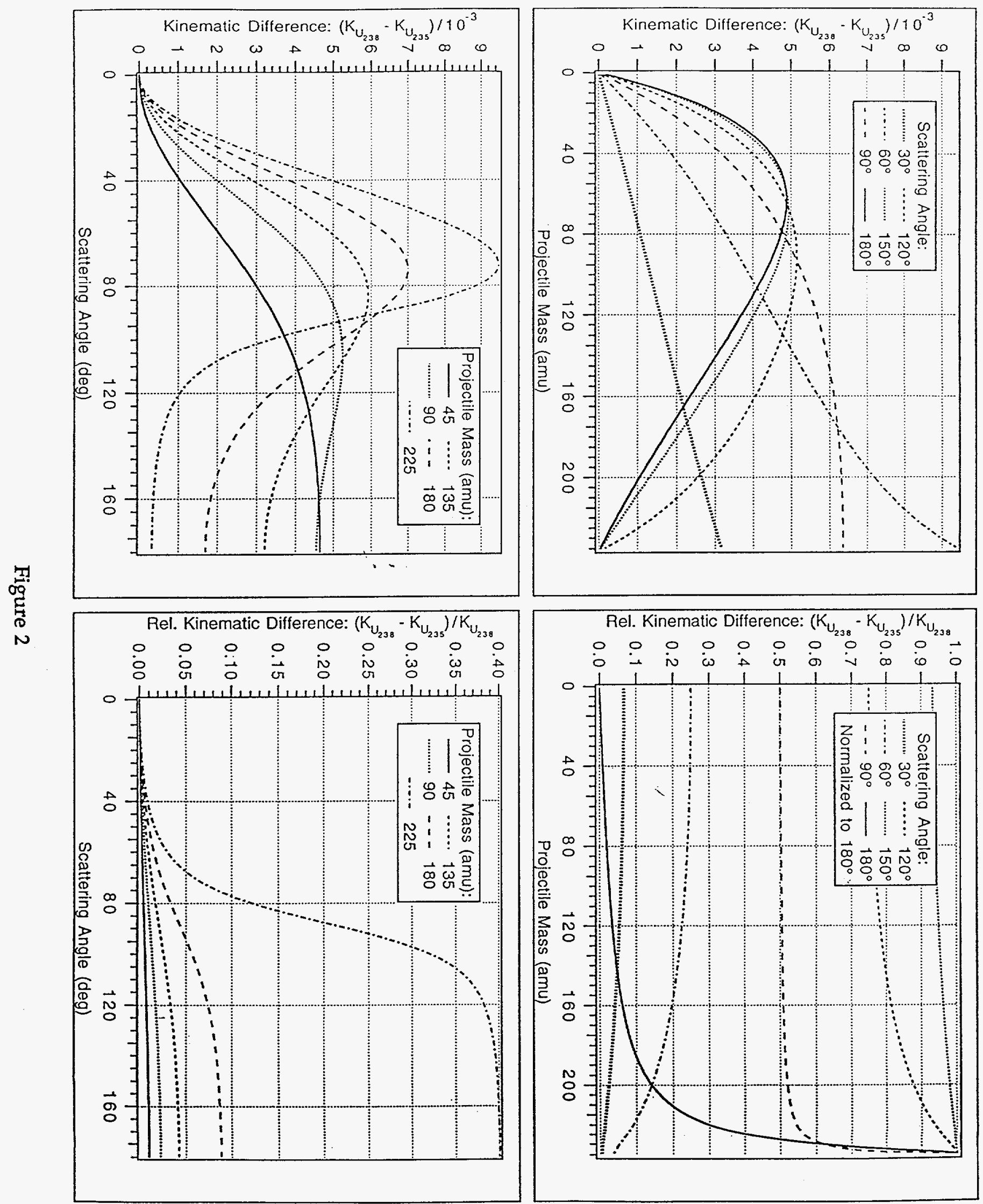


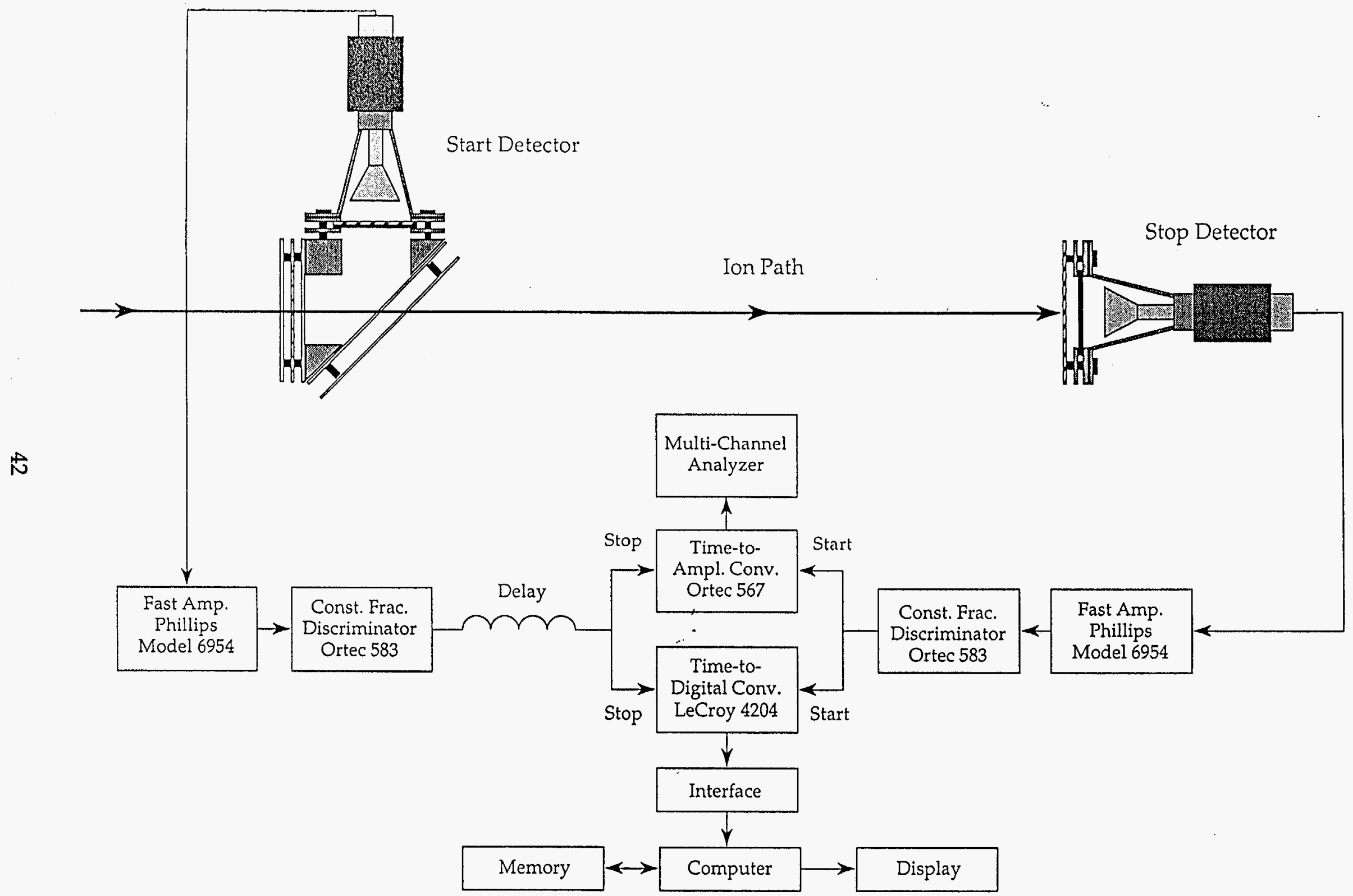

Figure 3 


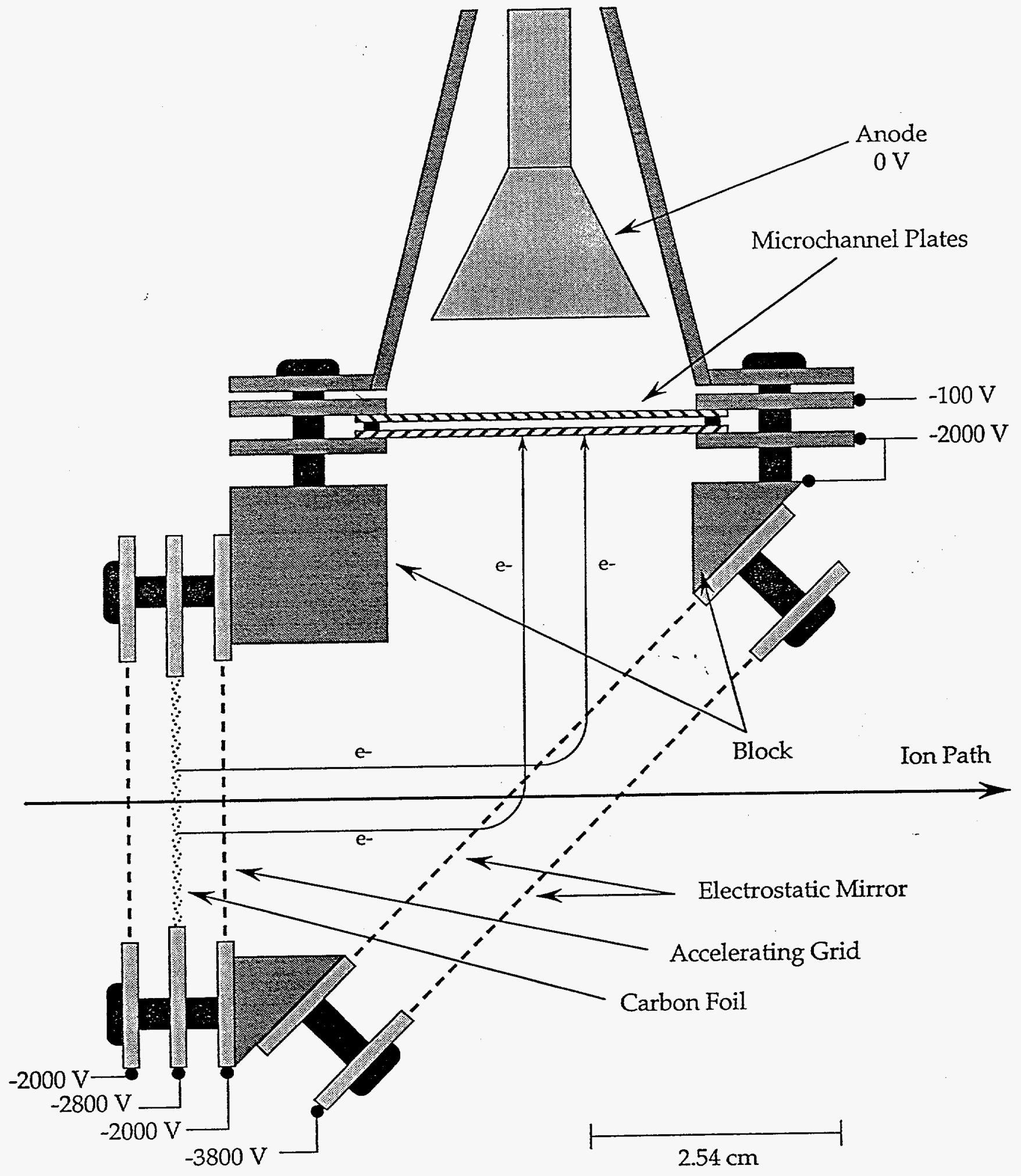

Figure 4 

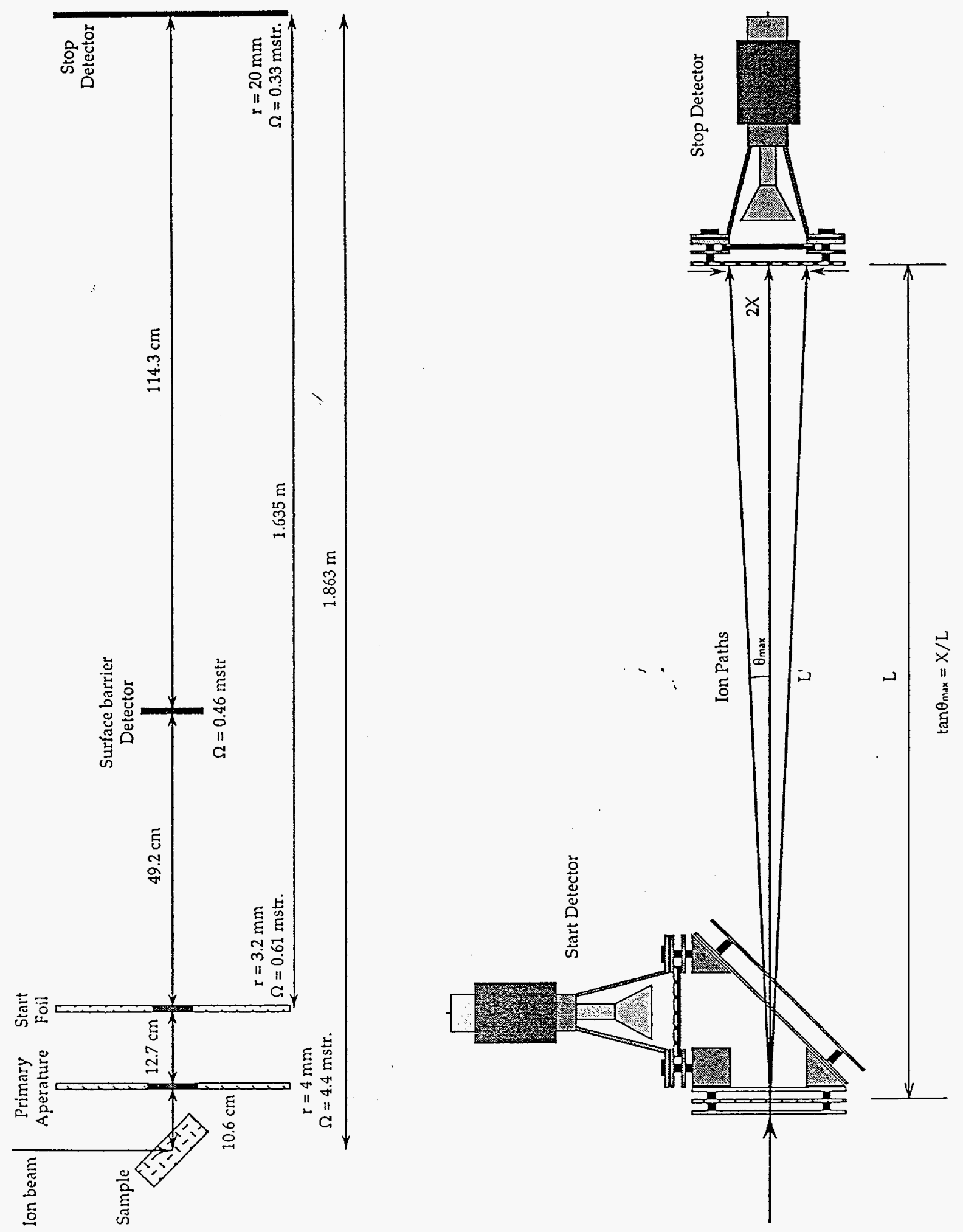


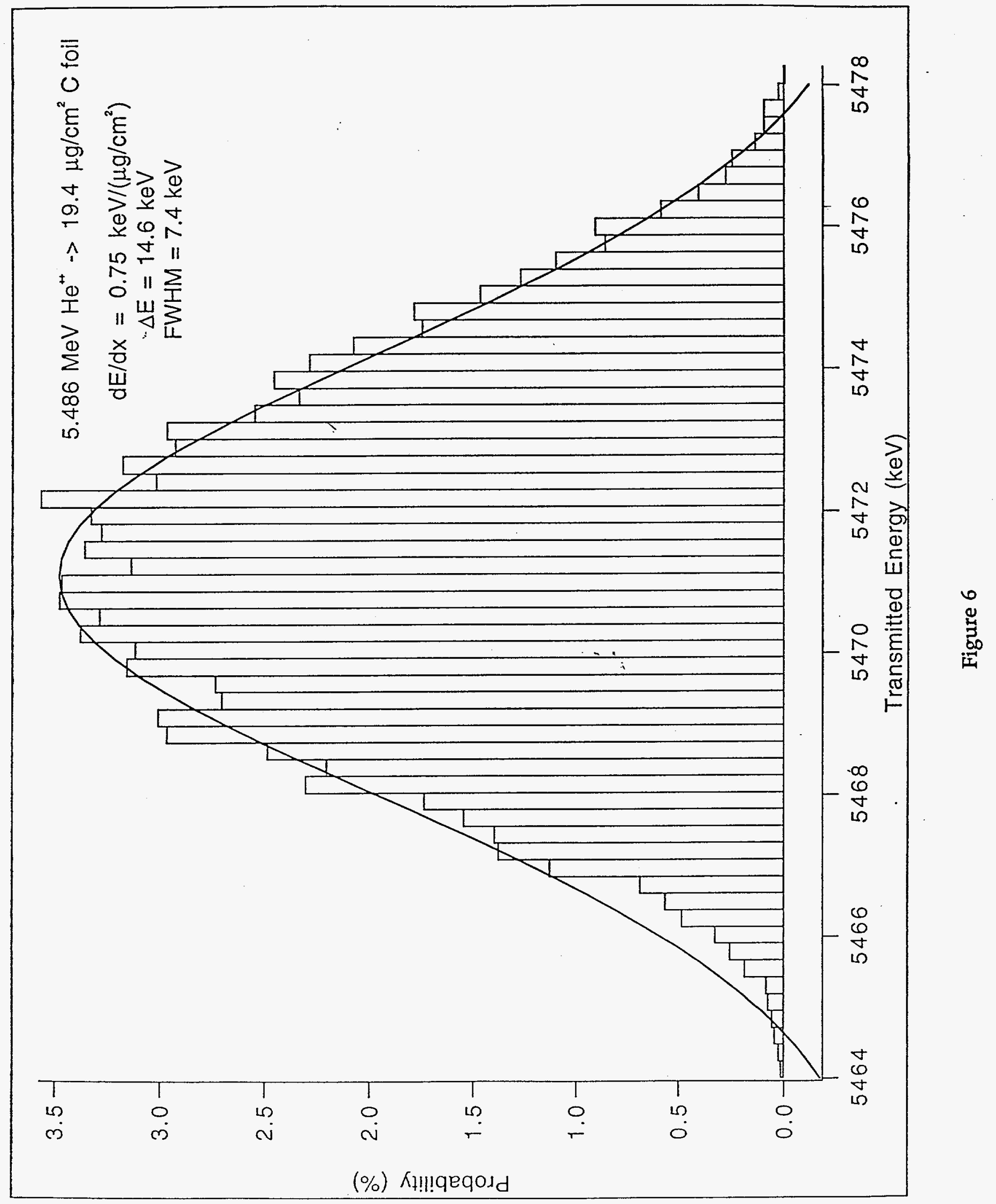


TOF Spectrum
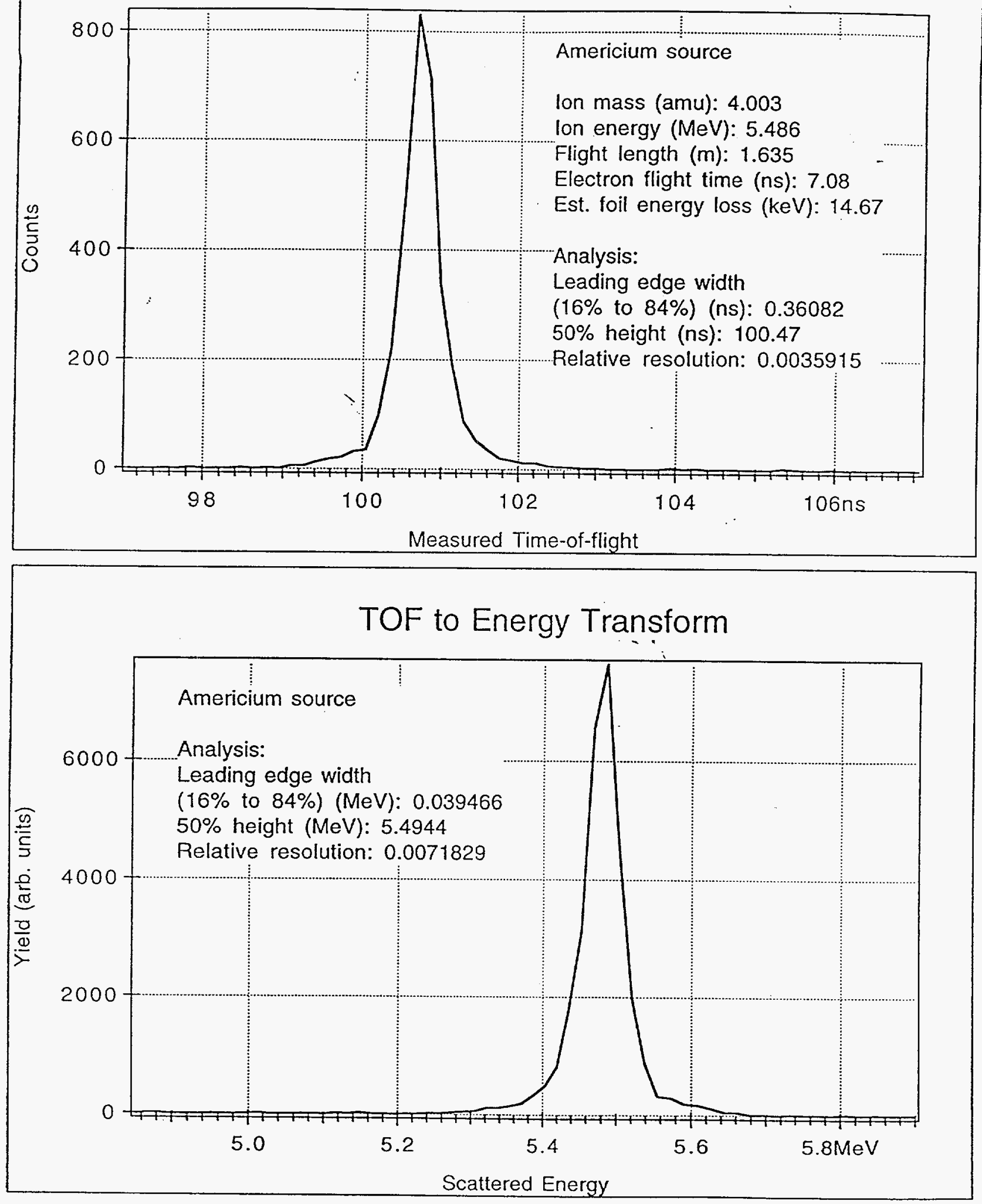

Figure 7 


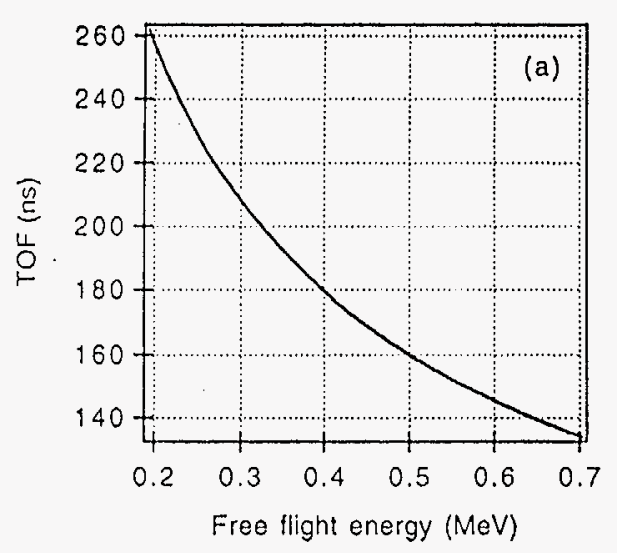

\section{Energy resolution analysis}

से

$Z_{1}=1$

Ion mass $=1.008 \mathrm{amu}$

Flight length $=1.635 \mathrm{~m}$

Stop channel plate dia. $=40 \mathrm{~mm}$

Timing error $\left(\delta \mathrm{t}_{\mathrm{e}}\right)=0.361 \mathrm{~ns}$

Accelerator ripple $=2.5 \mathrm{keV}$

Electron flight time $=7 \mathrm{~ns}$

Carbon foil $=19.4 \pm 10 \% \mu \mathrm{g} / \mathrm{cm} 2$ $=858.41 \AA$

$\mathrm{dE} / \mathrm{dx}=0.361 \mathrm{keV} /(\mu \mathrm{g} / \mathrm{cm} 2)$

Energy loss $=7.0034 \mathrm{keV}$

Straggling $=1.2337 \mathrm{keV}$

Uniformity error $=0.70034 \mathrm{keV}$

Total energy error $(\delta \mathrm{E})=2.8744 \mathrm{keV}$
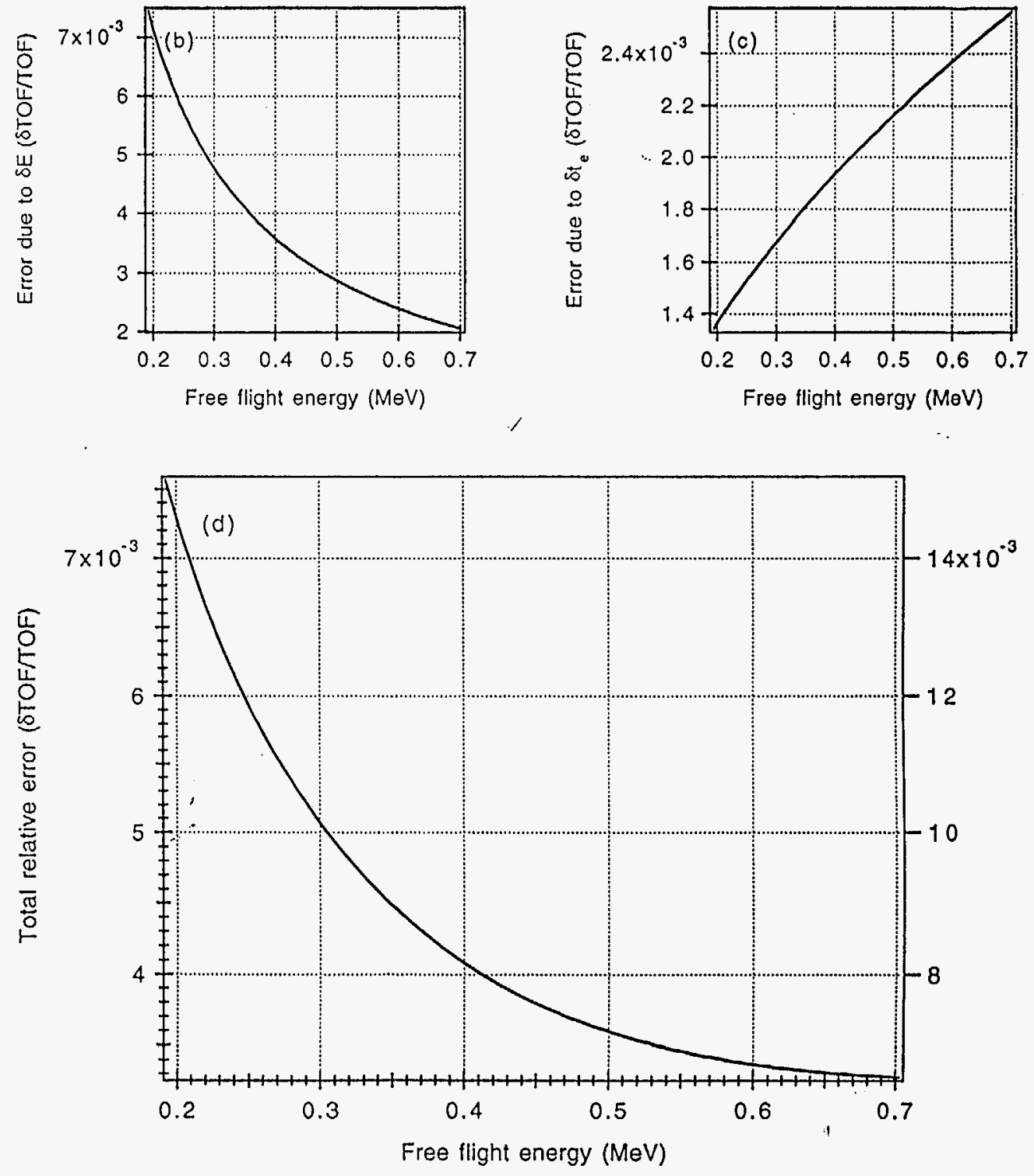

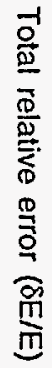

Figure 8 


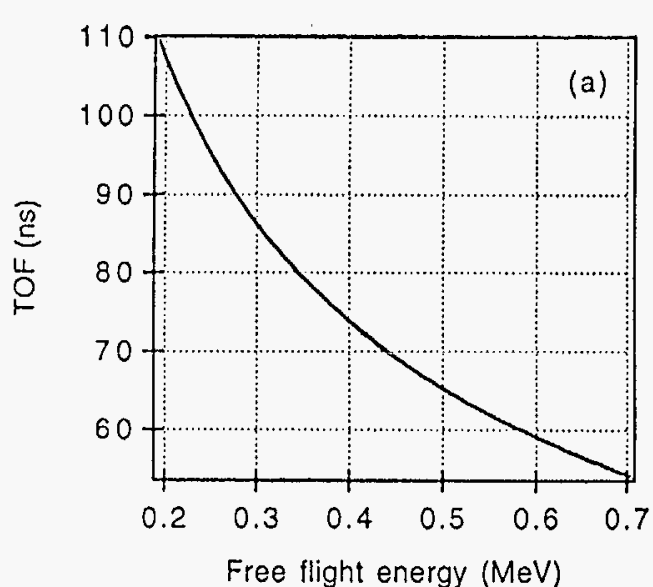

Energy resolution
analysis

$\infty$

$z_{1}=1$

Ion mass $=1.008 \mathrm{amu}$

Flight length $=0.708 \mathrm{~m}$

Stop channel plate dia. $=40 \mathrm{~mm}$

Timing error $\left(\delta t_{e}\right)=0.361 \mathrm{~ns}$

Accelerator ripple $=2.5 \mathrm{keV}$

Electron flight time $=7$ ns

Carbon foil $=19.4 \pm 10 \% \mu \mathrm{g} / \mathrm{cm} 2$

$=858.41 \AA$

$\mathrm{dE} / \mathrm{dx}=0.361 \mathrm{keV} /(\mu \mathrm{g} / \mathrm{cm} 2)$

Energy loss $=7.0034 \mathrm{keV}$

Straggling $=1.2337 \mathrm{keV}$

Uniformity error $=0.70034 \mathrm{keV}$

Total energy error $(\delta E)=2.8744 \mathrm{keV}$
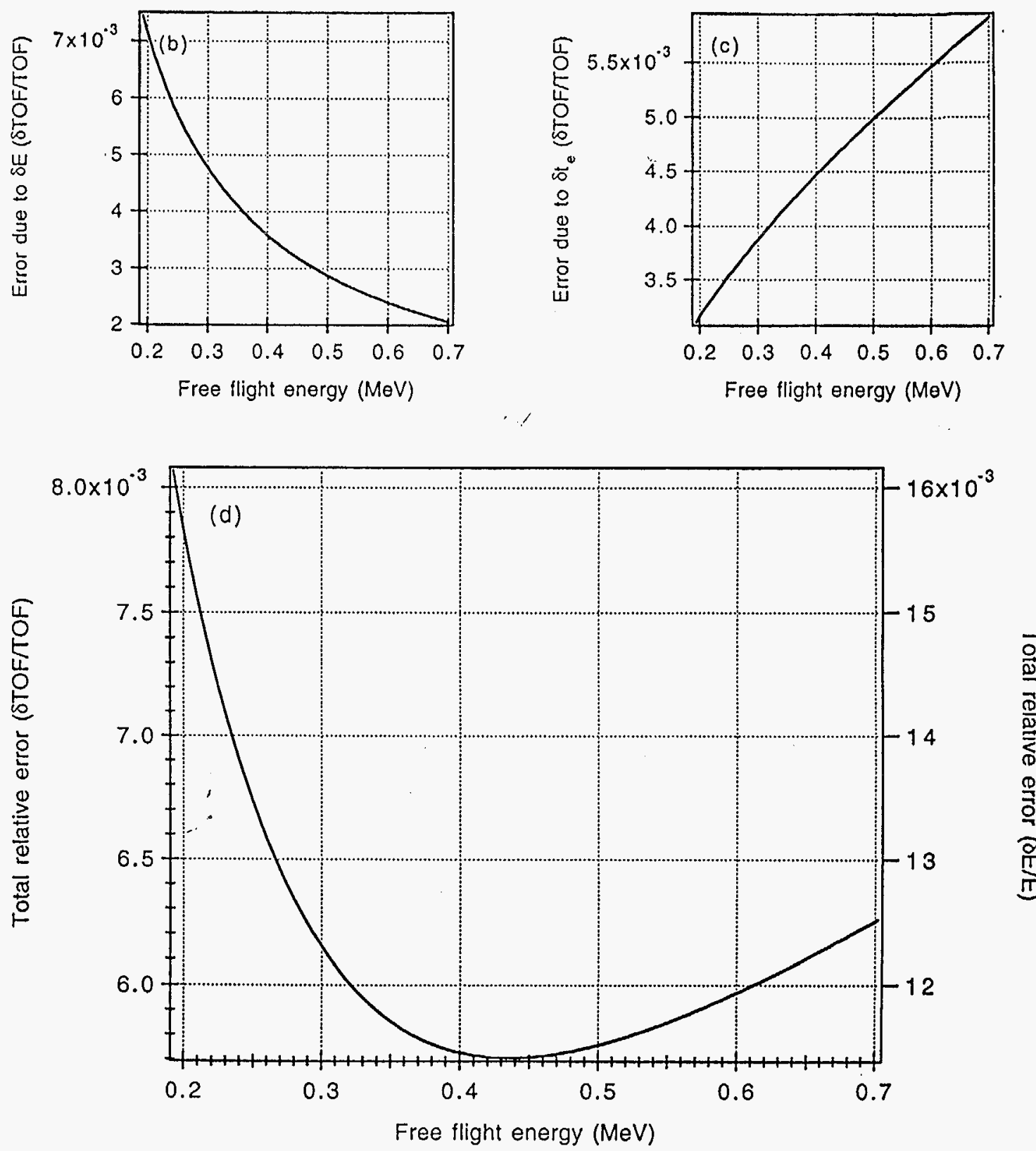

Figure 9 


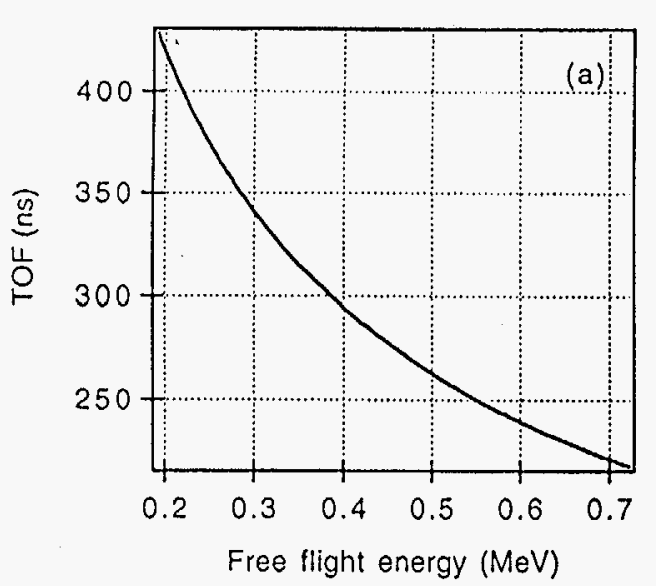

Energy resolution

出

$$
z_{1}=7
$$

Ion mass $=14.01 \mathrm{amu}$

Flight length $=0.708 \mathrm{~m}$

Stop channel plate dia. $=40 \mathrm{~mm}$

Timing error $\left(\delta \mathrm{t}_{\mathrm{e}}\right)=0.361 \mathrm{~ns}$

Accelerator ripple $=2.5 \mathrm{keV}$

Electron flight time $=7 \mathrm{~ns}$

Carbon foil $=19.4 \pm 10 \% \mu \mathrm{g} / \mathrm{cm} 2$

$$
=858.41 \AA
$$

$\mathrm{dE} / \mathrm{dx}=4.55 \mathrm{keV} /(\mu \mathrm{g} / \mathrm{cm} 2)$

Energy loss $=88.27 \mathrm{keV}$

Straggling $=8.6356 \mathrm{keV}$

Uniformity error $=8.827 \mathrm{keV}$

Total energy error $(\delta \mathrm{E})=12.599 \mathrm{keV}$
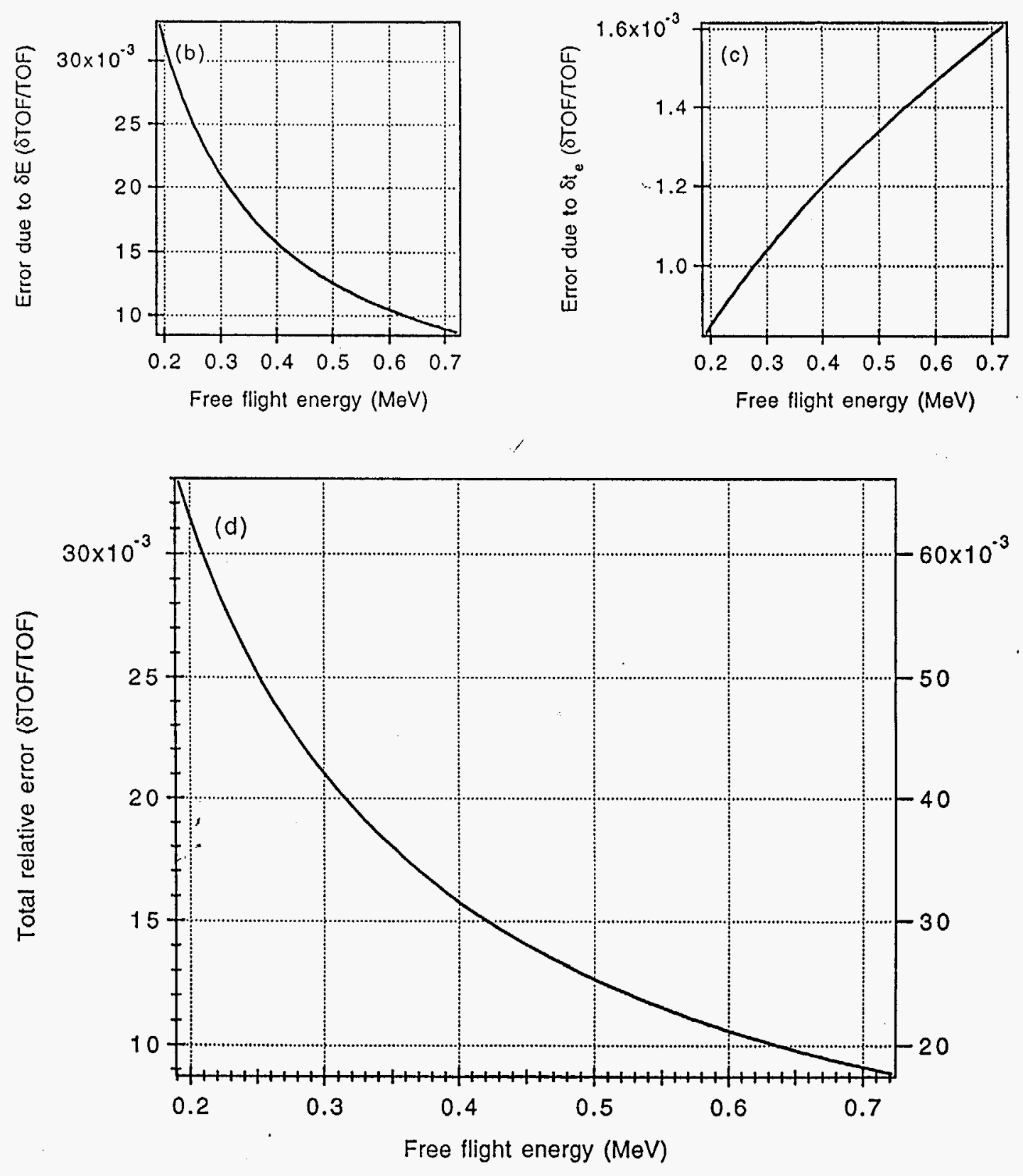

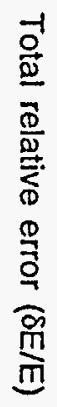



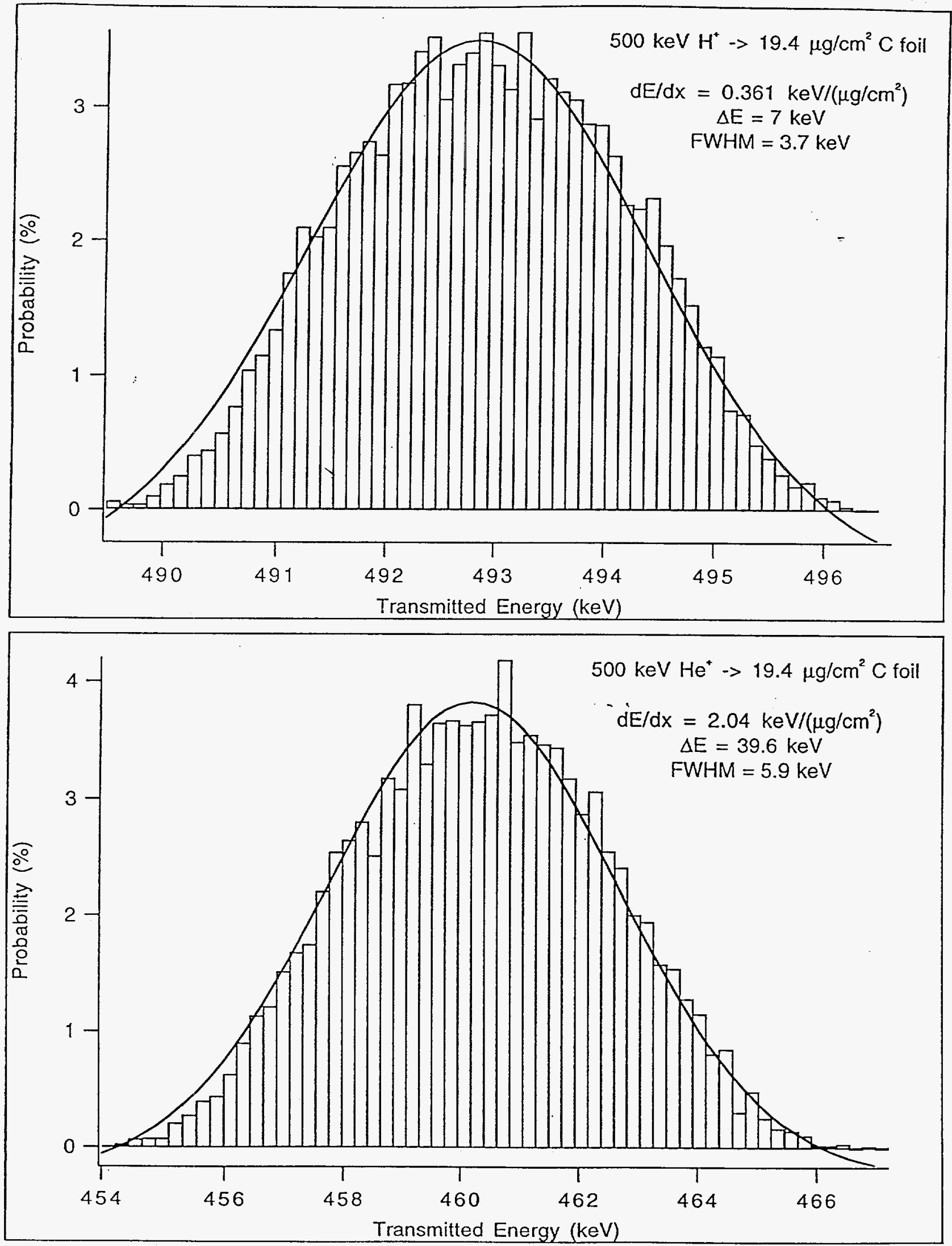

Figure 11 

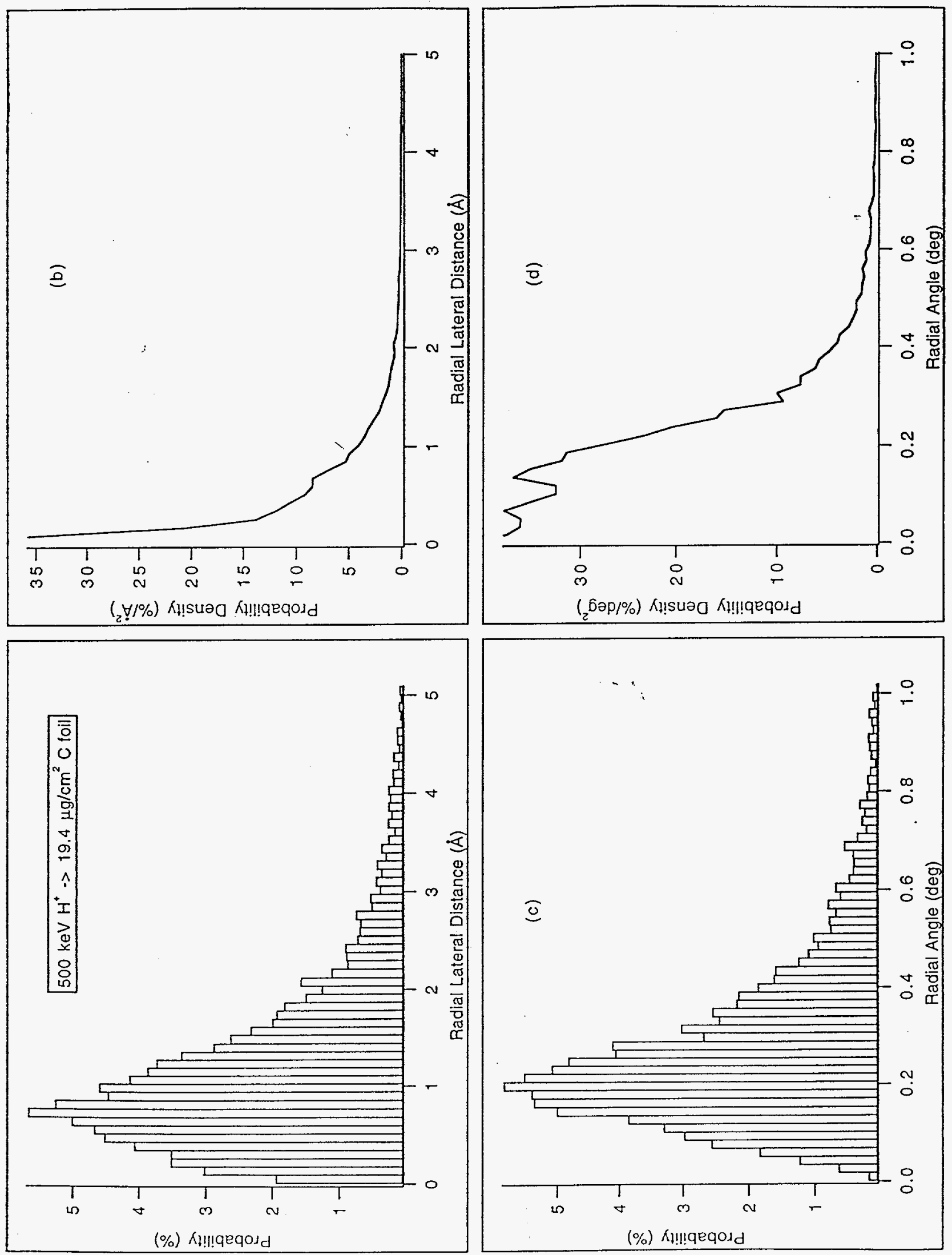

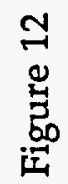



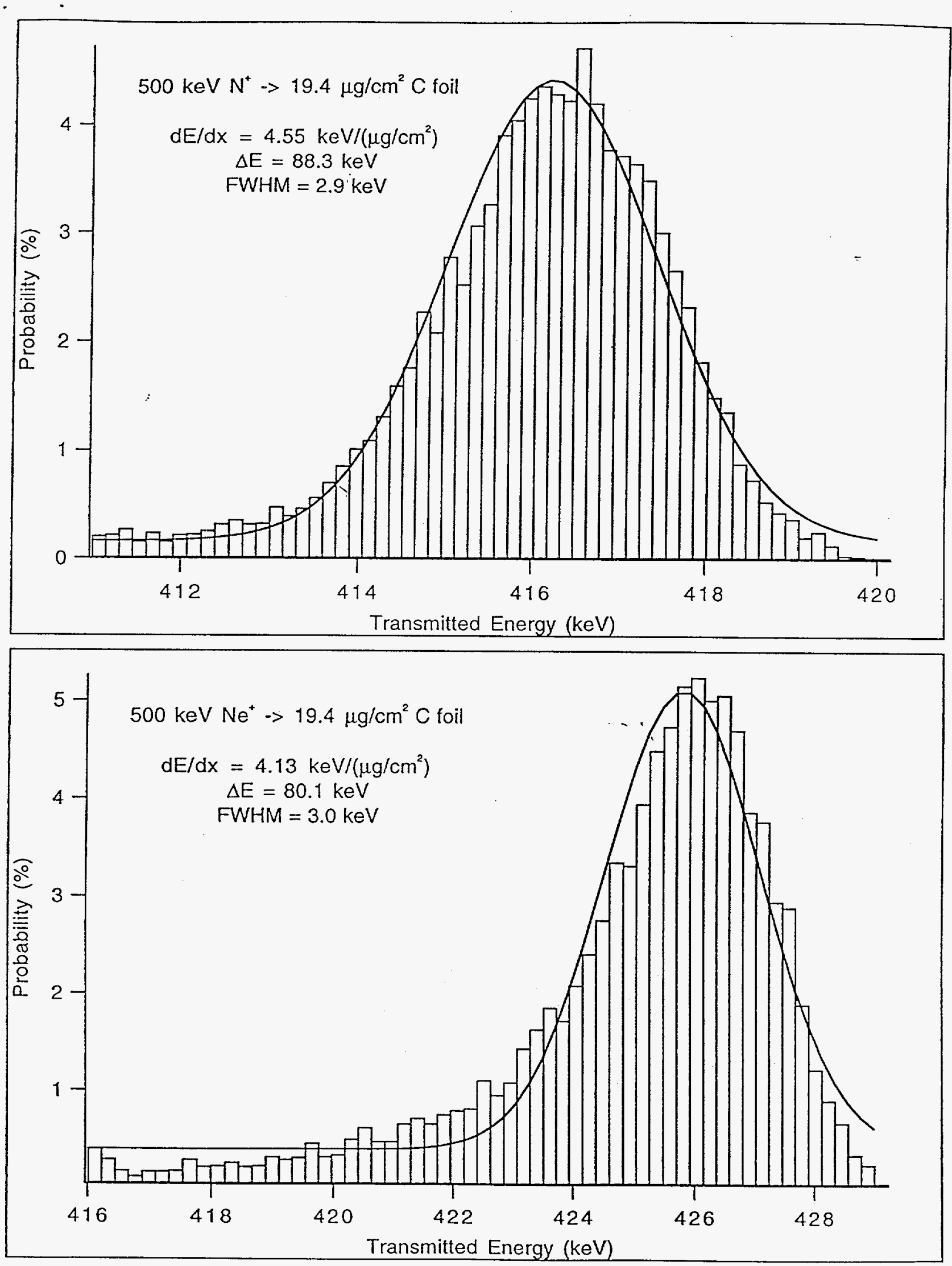

Figure 13 

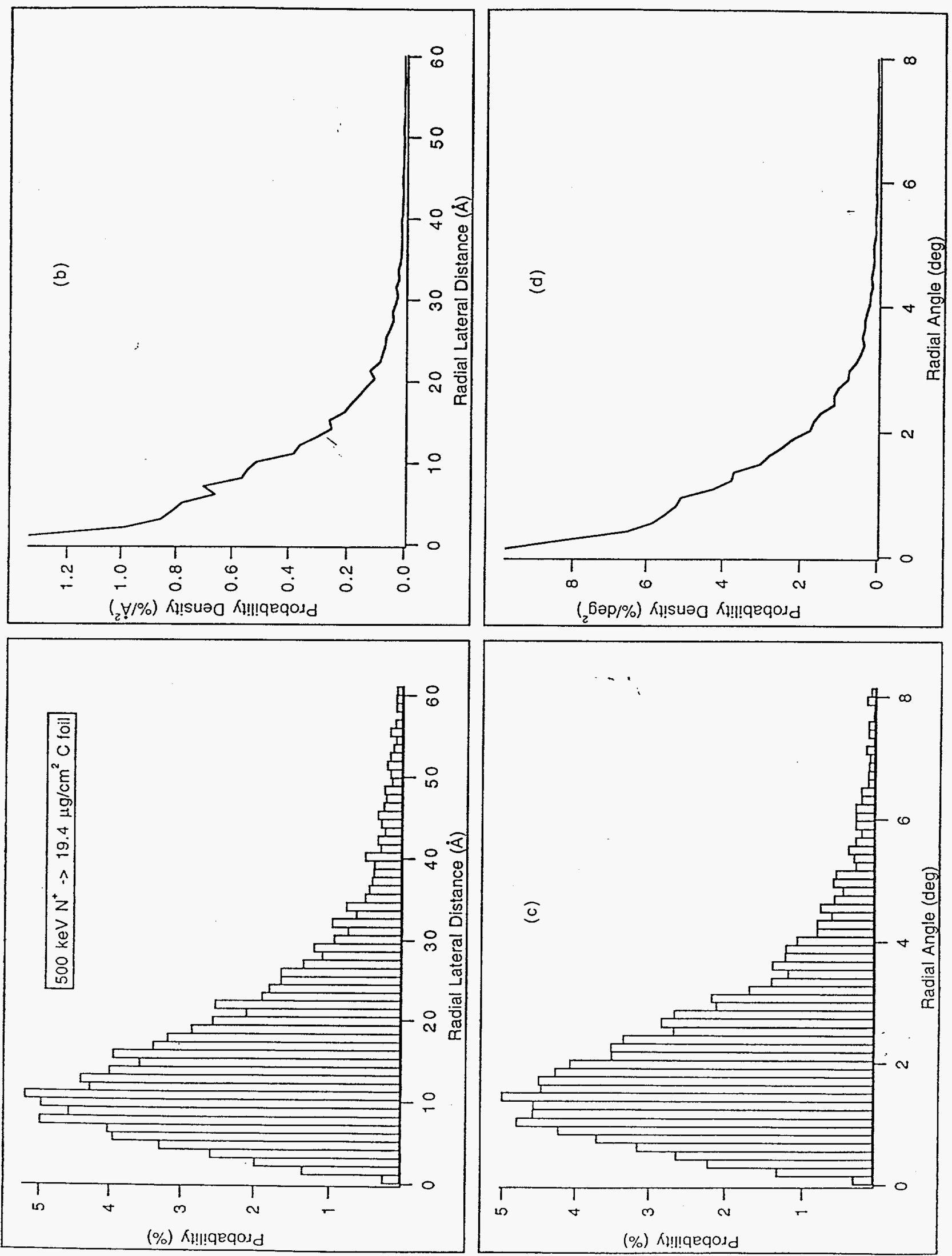

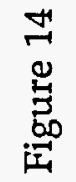



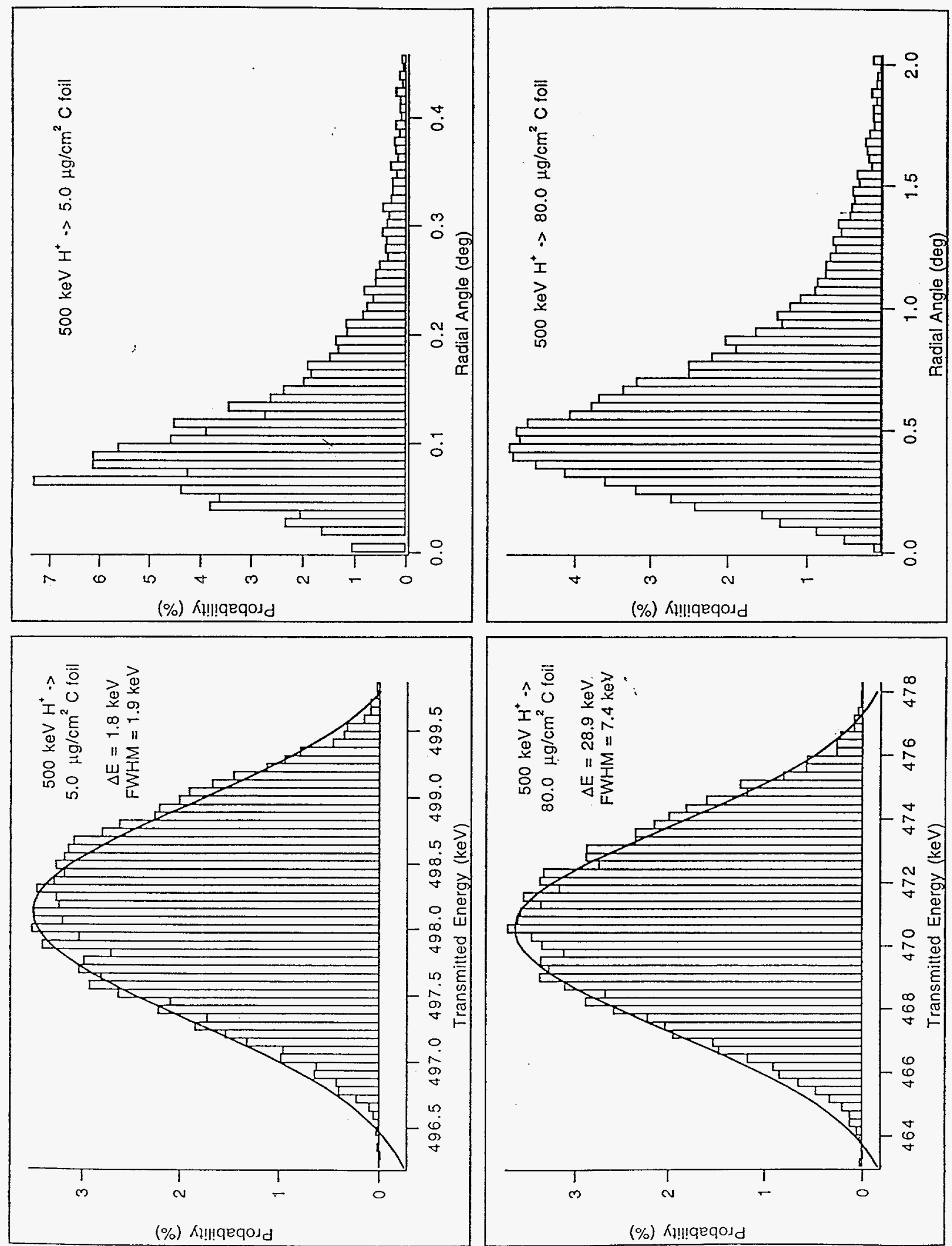

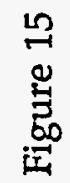

(\%) Kł!nqeqoud 

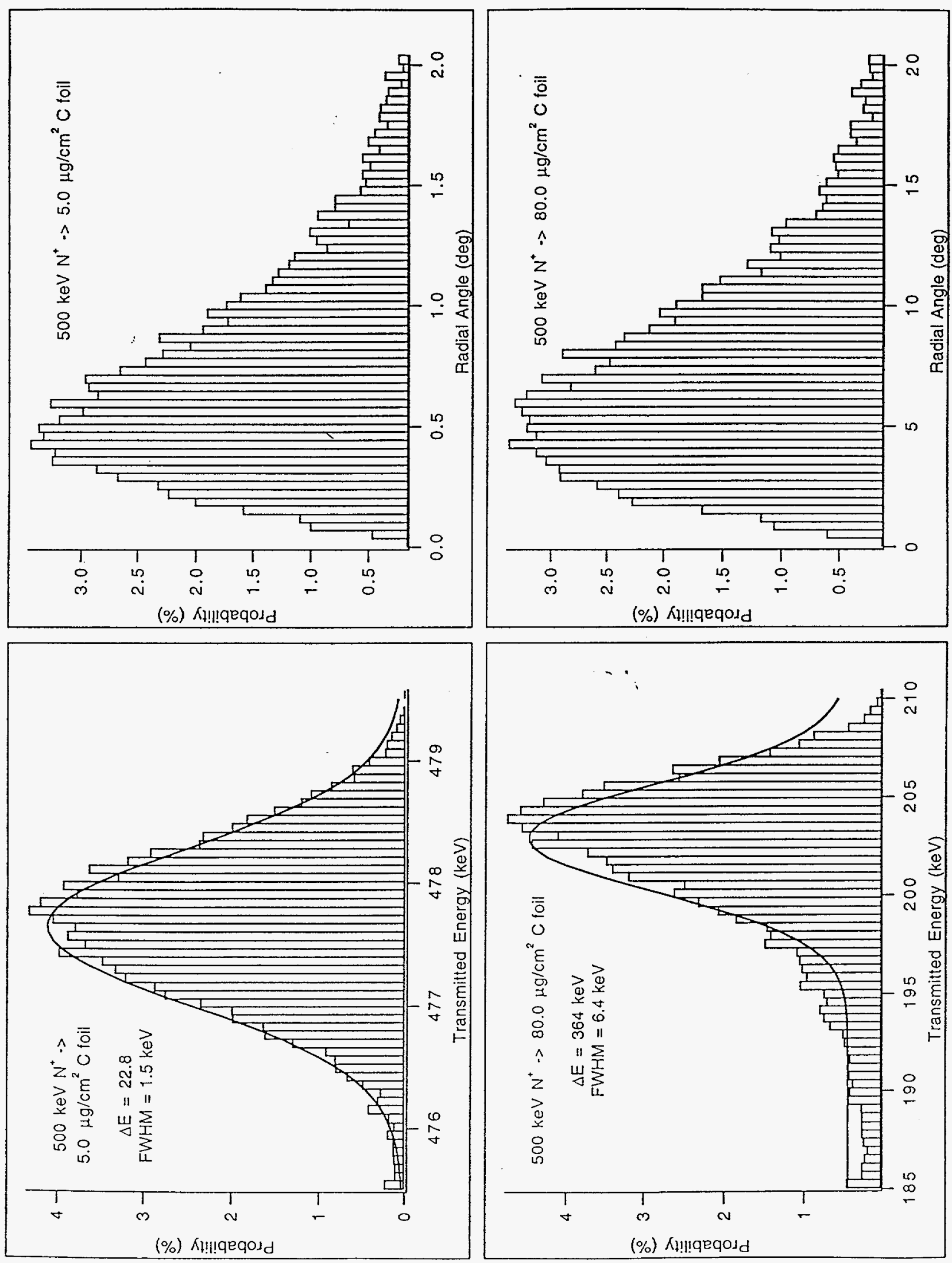

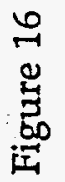




\section{TOF Spectrum}

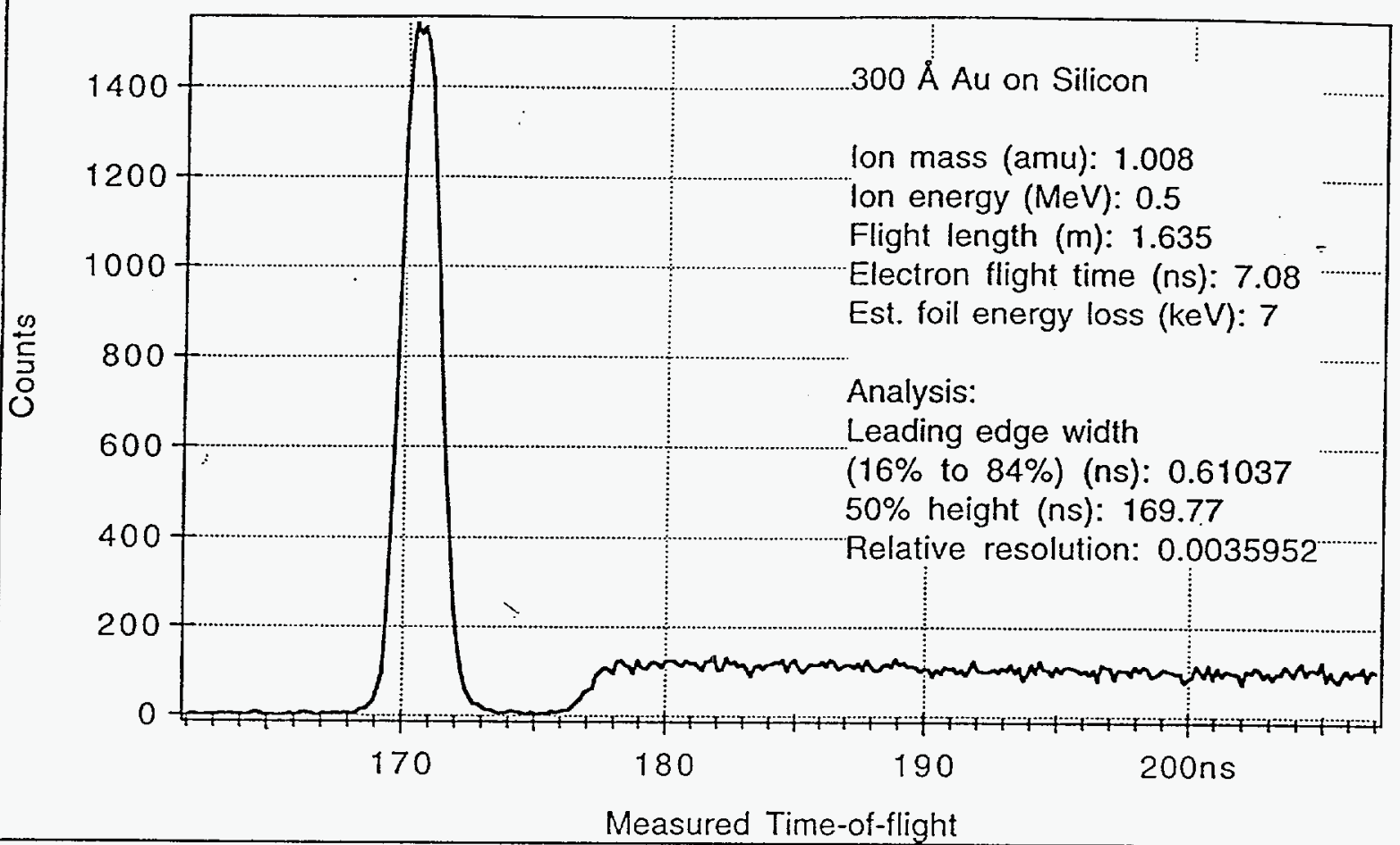

\section{TOF to Energy Transform}

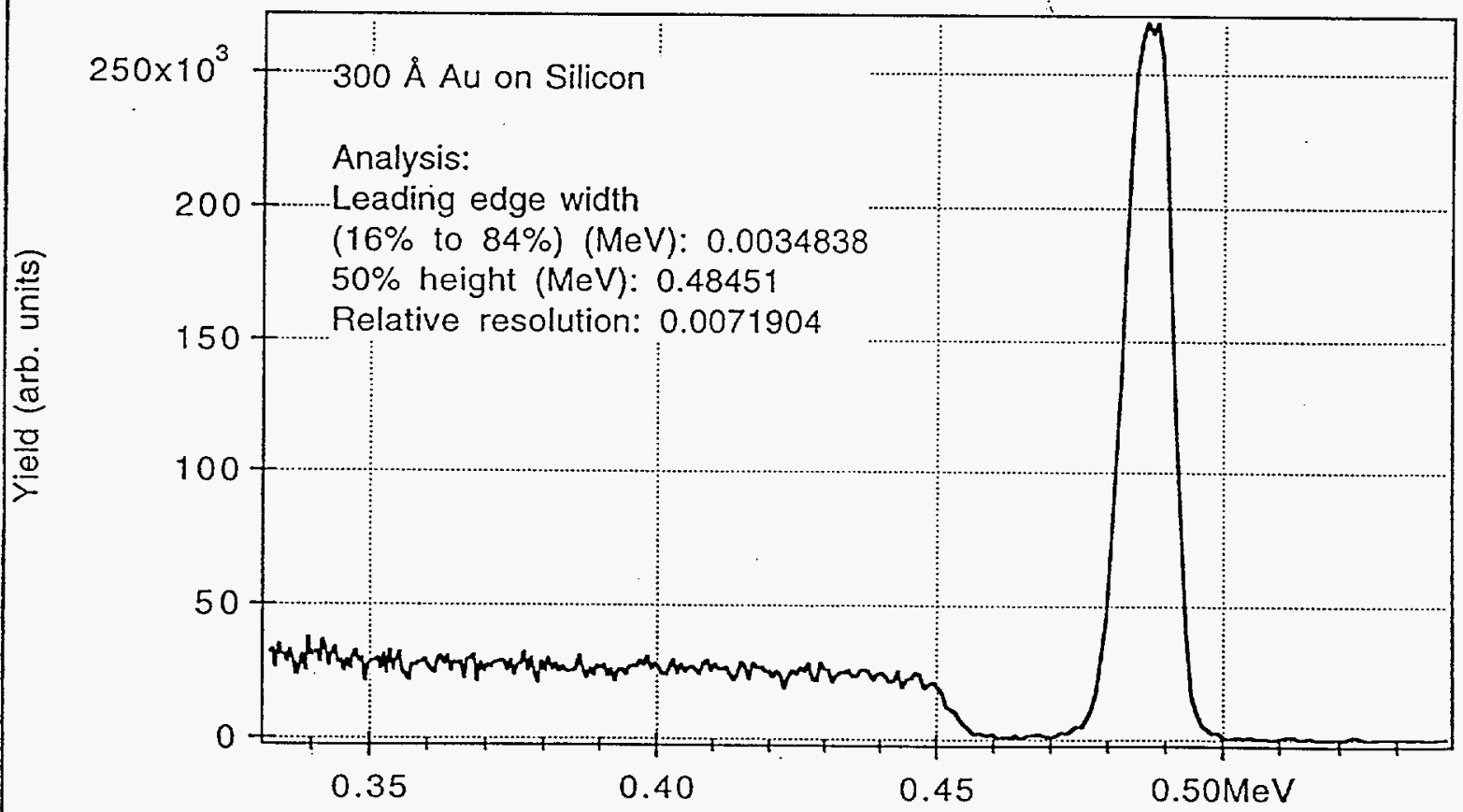

Scattered Energy

Figure 17 
TOF Spectrum

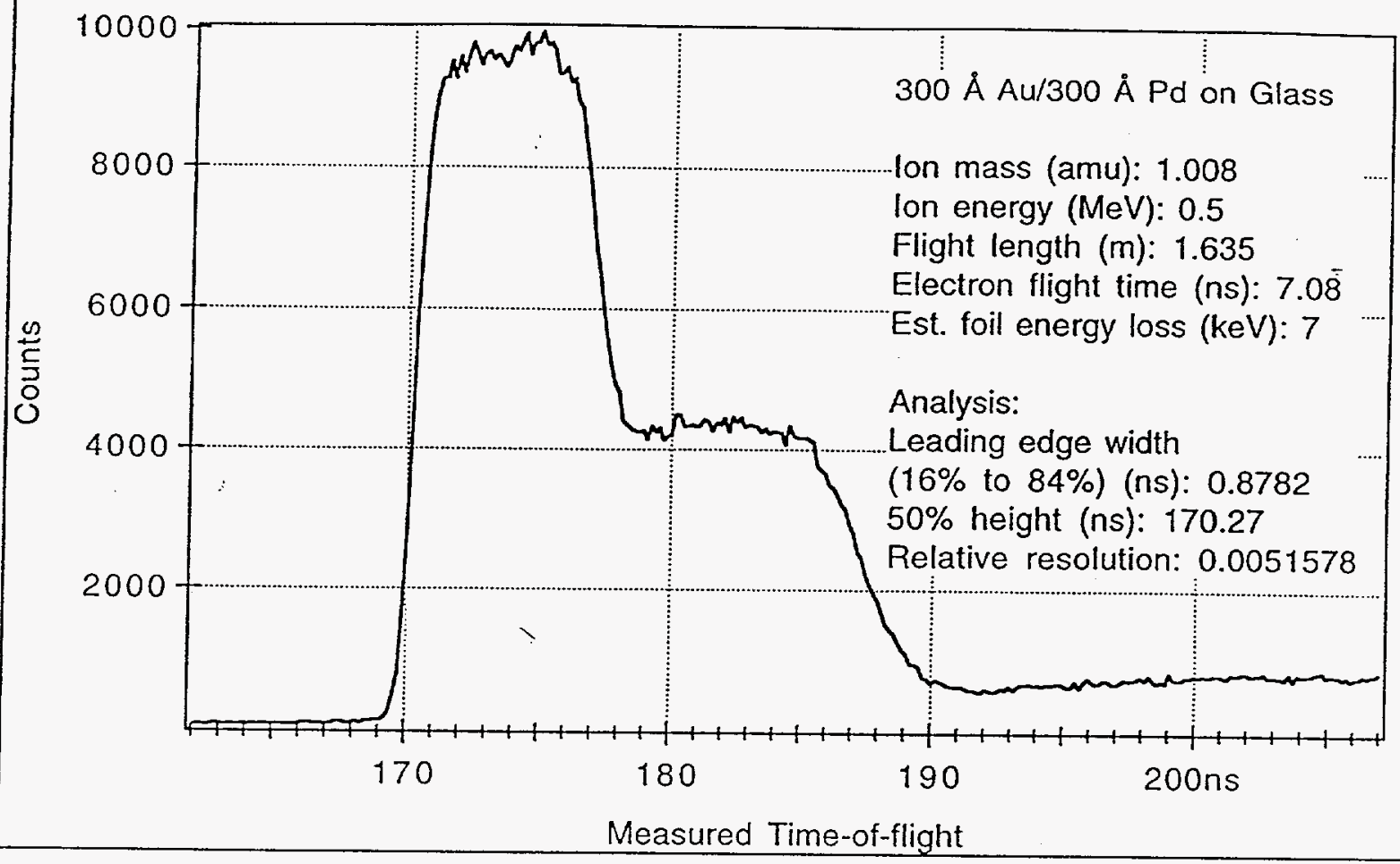

TOF to Energy Transform

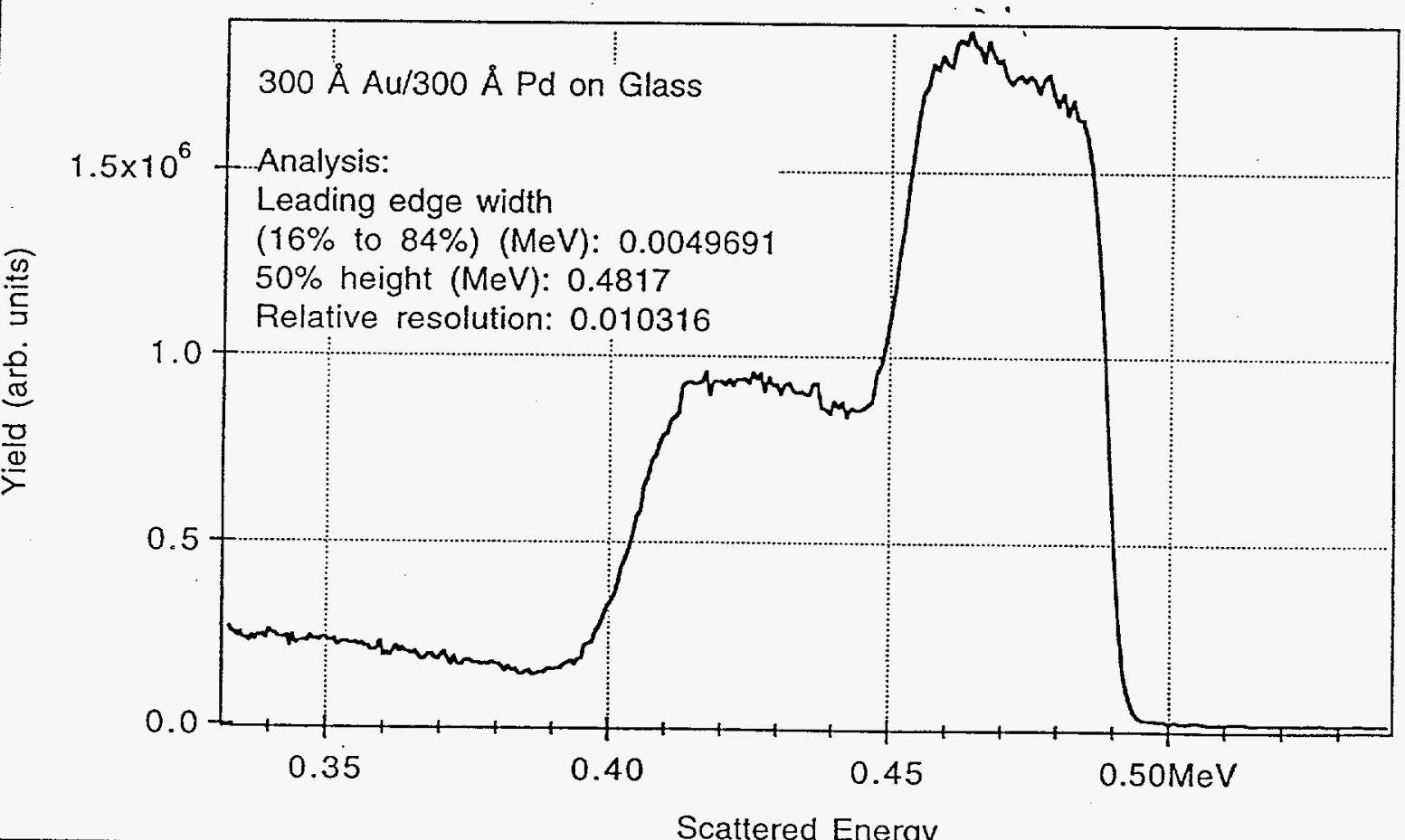

Figure 18 
UNLIMITED RELEASE

INITIAL DISTRIBUTION

U.S. Department of Energy

Rob Clemmer

Leslie Casey

Washington, DC

Maj. Robert Hartley

AFTAC

Brown University

Department of Chemistry

Attn: P. J. Estrup, Chairman

Providence, RI 02912

Iowa State University

Ames Laboratory

Attn: Prof. P. A. Thiel

Ames, IA 50011

Montana State University

Department of Physics

Attn: Richard Smith

Bozeman, MT 59717

Rutgers University

Dept. of Physics and Astronomy

P.O. Box 849

Attn: Torgny Gustafsson

Piscataway, NJ 08855-0849

University of California, Los Angeles

Department of Chemistry

Attn: Samir Anz (10)

UCLA

Los Angeles, CA 90024-1569

University of California, Los Angeles

Department of Chemistry

Attn: Prof. R. Stanley Williams (10)

UCLA

Los Angeles, CA 90024-1569 
AT\&T Bell Labs

Mater. Sci. \& Eng. Res. Div.

600 Mountain Ave.

Attn: L. C. Feldman

Murray Hill, NJ 07974

IBM

Thomas J. Watson Research Center

P.O. Box 218

Attn: R. M. Tromp

Yorktown Heights, NY 10598

G. S. Bench, LLNL, L-397

J. C. Davis, LLNL, L-270

D. W. Heikkinen, LLNL, L-397

Richard H. Howell, LLNL, L-280

J. McAninch, LLNL, L-397

R. G. Musket, LLNL, L-350

I. D. Proctor, LLNL, L-397

M. L. Roberts, LLNL, L-397

MS0336 R. J. Eagan, 1100

MS0337 A. Romig, 1800

MS0567 D. L. Mangan, 9208

MS0567 R. L. Courtney, 9208

MS0768 R. D. Horton, 5804

MS0815 R. L. Ewing, 5932

MS0970 T. A. Sellers, 9200

MS1056 B. L. Doyle, 1111

MS1056 S. R. Lee, 1111

MS1056 W. R. Wampler, 1112

MS1167 K. M. Horn, 9351

MS9001 J. C. Crawford, 8000

Attn: E. E. Ives, 5200

J. B. Wright, 5300

R. E. Detry, 8200

L. A. Hiles, 8400

P. N. Smith, 8500

L. A. West, 8600

T. M. Dyer, 8800

D. L. Crawford, 8900

MS9004 M. E. John, 8100

MS9054 W. J. McLean, 8300

MS9161 A. J. Antolak, 8341

MS9161 R. H. Stulen, 8342

MS9161 W. G. Wolfer, 8341 
MS9162 A. E. Pontau, 8347

MS9162 D. H. Morse, 8347

MS9162 R. James, 8347

MS9163 K. L. Wilson, 8304

MS9163 W. Bauer, 8302

MS9213 S. C. Johnston, 8103

MS9401 R. C. Wayne, 8700

MS9402 B. V. Hess, 8715

MS9402 G. J. Thomas, 8715

MS9402 M. Perra, 8714

MS9402 T. E. Felter, 8715 (10)

MS9403 J. M. Hruby, 8716

MS9403 M. Baskes, 8712

MS9405 D. L. Lindner, 5404

MS9022 Mail Distribution, 8533-1, OSTI (10)

MS9022 Mail Team Distribution, 8533-1

MS0899 Technical Library Department, 13414 (4)

MS9018 Central Technical Files, 8523-2 (3) 